\title{
Tsunami damping by mangrove forest: a laboratory study using parameterized trees
}

\author{
A. Strusińska-Correia ${ }^{1}$, S. Husrin ${ }^{1, *}$, and H. Oumeraci ${ }^{1}$ \\ ${ }^{1}$ Leichtweiß-Institute for Hydraulic Engineering and Water Resources (LWI), Department of Hydromechanics and Coastal \\ Engineering, Technische Universität Braunschweig, Germany \\ *now at: Research Institute of Coastal Resources and Vulnerability, Ministry of Marine and Fisheries Affairs, \\ Republic of Indonesia
}

Correspondence to: A. Strusińska-Correia (a.strusinska@tu-braunschweig.de)

Received: 14 August 2012 - Published in Nat. Hazards Earth Syst. Sci. Discuss.: -

Revised: 30 November 2012 - Accepted: 17 December 2012 - Published: 25 February 2013

\begin{abstract}
Tsunami attenuation by coastal vegetation was examined under laboratory conditions for mature mangroves Rhizophora sp. The developed novel tree parameterization concept, accounting for both bio-mechanical and structural tree properties, allowed to substitute the complex tree structure by a simplified tree model of identical hydraulic resistance. The most representative parameterized mangrove model was selected among the tested models with different frontal area and root density, based on hydraulic test results. The selected parameterized tree models were arranged in a forest model of different width and further tested systematically under varying incident tsunami conditions (solitary waves and tsunami bores). The damping performance of the forest models under these two flow regimes was compared in terms of wave height and force envelopes, wave transmission coefficient as well as drag and inertia coefficients. Unlike the previous studies, the results indicate a significant contribution of the foreshore topography to solitary wave energy reduction through wave breaking in comparison to that attributed to the forest itself. A similar rate of tsunami transmission (ca. $20 \%$ ) was achieved for both flow conditions (solitary waves and tsunami bores) and the widest forest (75 $\mathrm{m}$ in prototype) investigated. Drag coefficient $C_{\mathrm{D}}$ attributed to the solitary waves tends to be constant $\left(C_{\mathrm{D}}=1.5\right)$ over the investigated range of the Reynolds number.
\end{abstract}

\section{Introduction}

Following the observations made during the recent extreme tsunami events, controversial opinions were published on the performance of the coastal forests subject to extreme tsunami. Coastal ecosystems may indeed act as a buffer against tsunami through a reduction of water flow velocity and inundation depth, debris blockage, their life saving role for people washed away by waves, and formation of sand dunes resulting from sand accumulation in front of the forest (Shuto, 1987; Harada and Imamura, 2005). A number of publications and reports confirming the positive role of coastal vegetation in tsunami attenuation, and based predominantly on the qualitative evaluation of the pre- and post-tsunami situation in the affected areas, reached the public after the 2004 Indian Ocean tsunami event (e.g. Dahdouh-Guebas et al., 2005; UNEP Report, 2005; EJF Report, 2006). The very low number of casualties as well as minimal damage suffered by villages located behind green belts, which have been reported in comparison to non-vegetated areas, were attributed to the healthy conditions the local vegetation of sufficient width and density.

On the other hand, there were clear evidences of severe destruction of single trees or even entire forests through uprooting, bending or trunk breaking during past tsunami events (e.g. Shuto, 1987; Yanagisawa et al., 2009). The damage encompassed predominantly the first few tree rows facing an open sea, growing in estuaries or along channels as well as regions experiencing the maximum tsunami intensity. An extreme example is the damage of the forest in Rikuzentakata 
City (Japan) by the Tohoku 2011 tsunami. Only a single pine tree survived the tsunami attack, out of 70000 mature trees whose trunks were broken at heights of 1-2 $\mathrm{m}$ above the ground (EERI Report, 2011).

In spite of these contradictory opinions, it may be concluded that coastal forests might indeed provide an effective protection against tsunami up to a certain magnitude. The level of this protection is however conditioned by forest characteristics (i.e. tree species, tree age determining tree dimensions, tree health state, forest density, forest width, effect of shrubs), local bathymetrical and geographical features as well as soil properties (risk of uprooting).

A number of studies have been performed, aiming at the improvement of the prediction of wave attenuation by coastal vegetation and at the determination of the corresponding hydraulic resistance, including experimental investigations (e.g. Imai and Matsutomi, 2005; Irtem et al., 2009) as well as numerical modelling (e.g. Harada and Imamura, 2005; Ohira et al., 2012). The results of most of these investigations are representative for the mangrove Rhizophora sp., as its complex root system is believed to significantly contribute to the reduction of tsunami-induced flow. Among these, the experimental studies are of particular interest, since the existing methods of tree parameterization represent their weakest and most incomplete part. Although the parameterization procedure is determinant for the accuracy of the outcomes on the damping performance of the tested forest model, it seems to be of secondary importance and is either neglected (i.e. artificial plastic tree models are used) or based solely on the structural properties of the considered tree species (e.g. Kongko, 2004; Irtem et al., 2009).

Motivated by the lack of models to reliably predict the damping performance of coastal vegetation, the TAPFOR project ("Tsunami Attenuation Performance of Coastal Forests") was established to primarily provide a deep insight into the processes governing wave attenuation by mangrove and beach forests. Among the results of this project, only those related to the mangrove forests are addressed in this paper, including tree parameterization and the processes associated with wave and bore propagation and subsequent transmission behind the forest, as well the hydraulic resistance of mangroves subjected to both tsunami-like solitary waves and tsunami bores. More results and details can be found in Hus$\operatorname{rin}(2012)$.

\section{Parameterization of mangrove trees}

\subsection{Parameterization method}

A simplification of the very complex three-dimensional tree structure with randomly distributed roots and branches was necessary for consistent modelling. Moreover, it allows one to reduce the efforts of constructing the tree models for the laboratory experiments. By applying a proper parameteriza-

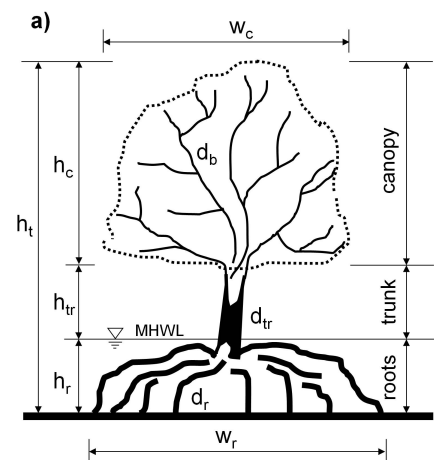

b)



Prototype tree dimensions adopted in this sudy (according to the suff stucture assumption, ic tree canopy not considered): $d_{r}=0.125 \mathrm{~m}, d_{t r}=0.2 \mathrm{~m}, h_{r}=0.5,1.0,1.5,2.5 \mathrm{~m}, h_{t}=5.0 \mathrm{~m}, h_{t r}=2.5 \mathrm{~m}$, $w_{r}=3.75 \mathrm{~m}$.

$d_{b}$ - branches diameter [m], $d_{r}$ - roots diameter $[\mathrm{m}], d_{t r}$ - trunk diameter $[\mathrm{m}], \mathrm{h}_{\mathrm{c}}$ - canopy height [m] $h_{r}$ - roots height [m], $h_{t}$ - tree height, $h_{t r}$ - trunk height, $w_{c}$ - canopy width [m], $w_{r}$ - width of area

occupied by roots [m]

Fig. 1. Geometry of a five-year old Rhizophora apiculata (a) and relationship between root density and water depth, obtained for mangrove models from model group A (low root density), B (medium root density) and $\mathrm{C}$ (high root density) in reference to field measurements by Mazda et al. (1997) (b).

tion approach (i.e. that accounts for both structural and biomechanical properties of the considered vegetation species), a prototype tree can be replaced by a model tree of a simplified structure having the same hydraulic resistance.

The selection of a representative mangrove species for the purposes of this study was conditioned by the criterion of maximum resistance of a tree subject to wave-induced flow, which in case of a single tree is determined predominantly by tree species and tree age (i.e. tree structural parts and their dimensions). A much higher rate of flow attenuation is expected in the case of a complex and denser root system, such as prop roots typical for red mangroves (Rhizophora sp.), than for other mangrove species (Fig. 1a). The canopy would however contribute to flow attenuation only in the case of large inundation depths reaching even the tree tops.

The parameterization method in this study was applied to a mature Rhizophora sp. under the stiff tree structure assumption, in which the contribution of the flexible canopy to wave damping was first neglected and the trunk was considered as stiff. In the first step, the typical dimensions of a five-year old red mangrove, provided by Mazda et al. (1997), Istiyanto et al. (2003) and Kongko (2004), were scaled down according to the Froude similitude law (see Fig. 1a). The relationship between submerged root volume ratio and water depth, obtained by Mazda et al. (1997) for different mangrove species in Japan and Australia, was used as a reference to determine the root density of the prototype tree (termed hereafter "real mangrove model"). Since the highest root density is attributed to the bottom part of the root system, a clear decrease of the submerged root volume ratio (defined as a volume of submerged mangrove roots $V_{\mathrm{m}}$ divided by water control volume $V$ ) with increasing water depth can be noticed 
Table 1. Influence of model submergence depth on the parameters of "real" and parameterized mangrove models (scale $1: 20$ ) (see also Fig. 2).

\begin{tabular}{|c|c|c|c|c|c|c|c|c|c|}
\hline \multicolumn{10}{|c|}{ Model group A (low root density) } \\
\hline \multirow[t]{2}{*}{$h / h_{\text {mdl }}[-]$} & \multirow[t]{2}{*}{$\mathrm{V}_{\mathrm{m}}\left[\mathrm{cm}^{3}\right]$} & \multicolumn{2}{|c|}{ A1 } & \multicolumn{2}{|c|}{ A2 } & \multicolumn{2}{|c|}{ A3 } & \multicolumn{2}{|c|}{ A4 } \\
\hline & & $A_{\mathrm{f}}\left[\mathrm{cm}^{2}\right]$ & $A_{\mathrm{p}}\left[\mathrm{cm}^{2}\right]$ & $A_{\mathrm{f}}\left[\mathrm{cm}^{2}\right]$ & $A_{\mathrm{p}}\left[\mathrm{cm}^{2}\right]$ & $A_{\mathrm{f}}\left[\mathrm{cm}^{2}\right]$ & $A_{\mathrm{p}}\left[\mathrm{cm}^{2}\right]$ & $A_{\mathrm{f}}\left[\mathrm{cm}^{2}\right]$ & $A_{\mathrm{p}}\left[\mathrm{cm}^{2}\right]$ \\
\hline 0.05 & 98.4 & 30.6 & 164.6 & 50.1 & 29.5 & 47.5 & 29.9 & 41.3 & 27.9 \\
\hline 0.10 & 124.6 & 52.1 & 164.6 & 75.3 & 29.5 & 65.0 & 29.9 & 56.3 & 27.9 \\
\hline 0.125 & 131.2 & 59.5 & 164.6 & 84.1 & 29.5 & 72.5 & 29.9 & 63.8 & 27.9 \\
\hline 0.15 & 133.2 & 61.8 & 164.6 & 86.6 & 29.5 & 75.0 & 29.9 & 66.3 & 27.9 \\
\hline \multicolumn{10}{|c|}{ Model group B (medium root density) } \\
\hline 0.05 & 164.0 & 34.7 & 248.1 & 65.1 & 39.7 & 47.5 & 40.0 & 45.0 & 42.0 \\
\hline 0.10 & 196.8 & 59.1 & 248.1 & 102.8 & 39.7 & 87.5 & 40.0 & 70.0 & 42.0 \\
\hline 0.125 & 229.6 & 67.4 & 248.1 & 116.6 & 39.7 & 122.5 & 40.0 & 107.5 & 42.0 \\
\hline 0.15 & 231.5 & 70.1 & 248.1 & 119.1 & 39.7 & 125.0 & 40.0 & 110.0 & 42.0 \\
\hline \multicolumn{10}{|c|}{ Model group C (high root density) } \\
\hline 0.05 & 328.0 & 56.9 & 361.2 & 72.6 & 95.5 & 74.3 & 92.7 & 84.0 & 80.9 \\
\hline 0.10 & 452.6 & 97.0 & 361.2 & 119.1 & 95.5 & 124.6 & 92.7 & 166.1 & 80.9 \\
\hline 0.125 & 505.1 & 110.6 & 361.2 & 140.4 & 95.5 & 145.7 & 92.7 & 167.3 & 80.9 \\
\hline 0.15 & 507.1 & 115.1 & 361.2 & 142.9 & 95.5 & 148.2 & 92.7 & 171.1 & 80.9 \\
\hline
\end{tabular}

where $h_{\mathrm{mdl}}$ is the total height of mangrove model [m].

(Fig. 1b). Overall, three real mangrove models of different root density were constructed to investigate the influence of the submerged root volume ratio on the hydraulic resistance of the models: model A1 with low root density, model B1 with medium root density and model $\mathrm{C} 1$ with high root density (Fig. 2). The structure of the real mangrove models was shaped by means of wires covered by a clay layer and hardened in an oven.

In the second step, a simplification of the considered structural tree parts was introduced to the "real mangrove models". The trunk was constructed as a single cylinder of identical height and diameter for all mangrove models (Fig. 2 and Figs. A1-A3 in Appendix A). The complex root system was replaced by a group of cylinders of different height, diameter and spacing in order to account for different frontal areas $A_{\mathrm{f}}$ (i.e. the areas perpendicular to flow direction) and projected areas $A_{\mathrm{p}}$ (i.e. the areas seen from the bird view) as shown in Tables 1 and 2. The frontal and the projected areas of the tree model were determined by means of AutoCAD software from photos taken perpendicularly and parallel to the flow direction, respectively. More details of the tree parameterization method can be found in Husrin et al. (2012) and Husrin (2012).

\subsection{Hydrodynamic properties of real and parameterized mangrove models}

In order to select the most appropriate representation of the "real" mangrove model among the parameterized models for further testing in the wave flume (Sects. 4-6), comparison of hydrodynamic properties of the parameterized and the reference models was made. For this purpose, laboratory experiments were performed at a scale of $1: 20$ under quasi-steady flow conditions in a flume, which is ca. $26.6 \mathrm{~m}$ long, $0.6 \mathrm{~m}$ wide and $0.7 \mathrm{~m}$ high. A single tree model was installed on a $0.18 \mathrm{~m}$ high platform in the middle of the flume width. A wide range of Reynolds number $\left(\operatorname{Re} \sim 2.9 \times 10^{4}-9 \times 10^{5}\right)$ was obtained by varying the flow depth $h$ over the platform $(0.05,0.1,0.125$ and $0.15 \mathrm{~m})$ and the flow velocity $(0.2,0.5$, $0.75,1.0$ and $1.42 \mathrm{~m} \mathrm{~s}^{-1}$ ). The flow velocity corresponded to the tsunami onshore velocity of the order of $2-5 \mathrm{~m} \mathrm{~s}^{-1}$ in the field, as estimated by Fritz et al. (2006).

The flow-induced forces exerted on a single mangrove model, water free surface elevation and flow velocity were measured at a distance of $0.35 \mathrm{~m}$ in front of and behind the tree model by means of force transducers (FTS), wave gauges (WG) and acoustic Doppler velocimeters (ADV), respectively. The flow velocity was generally measured at three different heights $(0.03,0.05$ and $0.08 \mathrm{~m})$ except for the lowest flow depth, for which the measurement was performed at one height of $0.03 \mathrm{~m}$. Based on these measurements, depthaveraged flow velocity (calculated at a height of $0.4 \mathrm{~h}$ above the platform according to Ward and Trimble, 2004) was introduced (see Husrin, 2012).

The measured parameters were used for the calculation of drag coefficient, the reduction of flow velocity and the hydraulic gradient (i.e. flow depth reduction over a given distance). A more detailed discussion of the experimental results is provided by Husrin (2012). A comparison of the drag coefficients of the parameterized mangrove models, 




Fig. 2. "Real mangrove models" of different root density with corresponding parameterized mangrove models of varying frontal and projected areas. Root density in model groups $\mathrm{A}, \mathrm{B}$ and $\mathrm{C}$ is constant.

with the reference values obtained for the "real mangrove models" was however particularly important for the selection of the parameterized model for further investigation in the wave flume. Drag coefficient $C_{\mathrm{D}}$ was calculated according to Morison's equation, assuming that inertia force can be neglected due to quasi-constant flow velocity, i.e. $\partial u / \partial t \sim 0$ :

$F_{\text {meas }}=\frac{1}{2} \rho \cdot C_{\mathrm{D}} \cdot A_{\mathrm{f}} \cdot u^{2}+\rho \cdot C_{\mathrm{M}} \cdot V_{\mathrm{m}} \cdot \frac{\partial u}{\partial t}$

$C_{\mathrm{D}}=\frac{2 F_{\text {meas }}}{\rho \cdot A_{\mathrm{f}} \cdot u^{2}}$,

where $A_{\mathrm{f}}$ is the frontal area of the mangrove model $\left[\mathrm{m}^{2}\right]$, listed in Table $1, C_{\mathrm{D}}$ the drag coefficient [-], $C_{\mathrm{M}}$ the inertia coefficient $[-]\left(C_{\mathrm{M}}=0.0\right), F_{\text {meas }}$ the measured flow-induced forces [N], $V_{\mathrm{m}}$ the volume of the submerged mangrove model $\left[\mathrm{m}^{3}\right]$, listed in Table 1, $u$ the depth-averaged horizontal flow velocity $\left[\mathrm{m} \mathrm{s}^{-1}\right], \rho$ the water density $\left[\mathrm{kg} \mathrm{m}^{-3}\right]$ and $\partial u / \partial t$ the horizontal flow acceleration $\left[\mathrm{m} \mathrm{s}^{-2}\right]$.

The behaviour of the calculated drag coefficient for the investigated range of Reynolds number $R e$ is shown in Fig. 3. The latter was redefined according to Mazda et al. (1997) in order to account for the physical properties of the tree models:

$R e=\frac{u \cdot L_{\mathrm{e}}}{v}$, with $L_{\mathrm{e}}$ denoting the effective length of the mangrove model $[\mathrm{m}]$, Re the Reynolds number [-] and $v$ the kinematic viscosity $\left[\mathrm{m}^{2} \mathrm{~s}^{-1}\right]$. The effective model length was specified as:

$L_{\mathrm{e}}=\frac{V-V_{\mathrm{m}}}{A_{\mathrm{f}}}$,

where $V$ represents the control water volume $\left[\mathrm{m}^{3}\right]$, defined as product of the tree model base area $(0.175 \mathrm{~m} \times 0.175 \mathrm{~m}$ at a scale of $1: 20$ ) and the flow depth.

A further analysis of the relationship between drag coefficient $C_{\mathrm{D}}$ and effective length $L_{\mathrm{e}}$ of the models indicated that larger $C_{\mathrm{D}}$ values were obtained for mangrove models of higher root density (i.e. smaller values of $L_{\mathrm{e}}$ ), which enabled the flow to pass through the root system. Instead, the flow around the tree model dominated the flow through the root system, thus generating vortices. In case of mangrove models with sparser roots (i.e. larger values of $L_{\mathrm{e}}$ ), the undisturbed flow through the root system was dominating, thus resulting in a weaker hydraulic resistance. A clear tendency of the drag coefficient to decrease, from $C_{\mathrm{D}}=10$ to $C_{\mathrm{D}}=1.0$, with the increasing Reynolds number can be noticed in Fig. 3. Empirical relationships to predict the drag coefficient for the given physical properties of the parameterized mangrove models and flow conditions are proposed:

$C_{\mathrm{D}}=1.69 \times 10^{3} R e^{-0.54}$, 
Table 2. Influence of model submergence depth on the parameters of "real" and parameterized mangrove models (scale $1: 20$ ) (see also Fig. 2 and Figs. A1-A3 in Appendix A).

\begin{tabular}{|c|c|c|c|c|c|c|c|c|c|c|c|c|c|}
\hline \multicolumn{2}{|c|}{ Structural tree part } & \multicolumn{4}{|c|}{$\begin{array}{l}\text { Model group A } \\
\text { (low root density) }\end{array}$} & \multicolumn{4}{|c|}{$\begin{array}{c}\text { Model group B } \\
\text { (medium root density) }\end{array}$} & \multicolumn{4}{|c|}{$\begin{array}{l}\text { Model group C } \\
\text { (high root density) }\end{array}$} \\
\hline & & A1 & $\mathrm{A} 2$ & A 3 & A4 & B1 & $\mathrm{B} 2$ & B3 & B4 & $\mathrm{C} 1$ & $\mathrm{C} 2$ & $\mathrm{C} 3$ & $\mathrm{C} 4$ \\
\hline \multirow[t]{3}{*}{ Trunk } & No. & 1 & 1 & 1 & 1 & 1 & 1 & 1 & 1 & 1 & 1 & 1 & 1 \\
\hline & Hght. & 15 & 15 & 15 & 15 & 15 & 15 & 15 & 15 & 15 & 15 & 15 & 15 \\
\hline & Diam. & 1 & 1 & 1 & 1 & 1 & 1 & 1 & 1 & 1 & 1 & 1 & 1 \\
\hline \multirow[t]{3}{*}{ Roots (type I) } & No. & 9 & 12 & 4 & 2 & 12 & 20 & 8 & 4 & 16 & 96 & 24 & 12 \\
\hline & Hght. & - & 12.5 & 12.5 & 12.5 & - & 12.5 & 12.5 & 12.5 & - & 12.5 & 12.5 & 12.5 \\
\hline & Diam. & 0.6 & 0.5 & 1.0 & 1.5 & 0.6 & 0.5 & 1.0 & 1.5 & 0.6 & 0.5 & 1.0 & 1.5 \\
\hline \multirow[t]{3}{*}{ Roots (type II) } & No. & 26 & 0 & 0 & 0 & 40 & 12 & 0 & 0 & 40 & 0 & 0 & 0 \\
\hline & Hght. & - & 10 & 10 & 10 & - & 10 & 10 & 10 & - & 10 & 10 & 10 \\
\hline & Diam. & 0.4 & 0.5 & 1.0 & 1.5 & 0.4 & 0.5 & 1.0 & 1.5 & 0.4 & 0.5 & 1.0 & 1.5 \\
\hline \multirow[t]{3}{*}{ Roots (type III) } & No. & 20 & 20 & 4 & 2 & 40 & 28 & 8 & 0 & 40 & 44 & 12 & 0 \\
\hline & Hght. & - & 7.5 & 7.5 & 7.5 & - & 7.5 & 7.5 & 7.5 & - & 7.5 & 7.5 & 7.5 \\
\hline & Diam. & 0.35 & 0.5 & 1.0 & 1.5 & 0.35 & 0.5 & 1.0 & 1.5 & 0.35 & 0.5 & 1.0 & 1.5 \\
\hline \multirow[t]{3}{*}{ Roots (type IV) } & No. & 25 & 28 & 8 & 4 & 63 & 80 & 8 & 8 & 150 & 52 & 12 & 12 \\
\hline & Hght. & - & 5.0 & 5.0 & 5.0 & - & 5.0 & 5.0 & 5.0 & - & 5.0 & 5.0 & 5.0 \\
\hline & Diam. & 0.3 & 0.5 & 1.0 & 1.5 & 0.3 & 0.5 & 1.0 & 1.5 & 0.3 & 0.5 & 1.0 & 1.5 \\
\hline \multirow[t]{3}{*}{ Roots (type V) } & No. & - & 74 & 18 & 4 & - & 46 & 20 & 10 & - & 474 & 66 & 20 \\
\hline & Hght. & - & 2.5 & 2.5 & 2.5 & - & 2.5 & 2.5 & 2.5 & - & 2.5 & 2.5 & 2.5 \\
\hline & Diam. & - & 0.5 & 1.0 & 1.5 & - & 0.5 & 1.0 & 1.5 & - & 0.5 & 1.0 & 1.5 \\
\hline
\end{tabular}

Roots (all types) Area occupied by roots $\left[\mathrm{m}^{2}\right] 17.5 \times 17.5$

where "No." is the number of structural tree parts [-], "Hght." the height of the structural tree parts [cm] and "Diam." the diameter of the structural tree parts [cm].

with a lower envelope of the data set given as:

$C_{\mathrm{D}}=1.0$.

The lower envelope of the data set is consistent with the values of the drag coefficient obtained from tests with a single cylinder subjected to steady flow, performed by Husrin (2012). A comparison of the obtained resistance from the parameterized mangrove models with the results from previous studies is provided in Sect. 6 below.

Based on the measurement of the flow-induced forces on the single tree models, it was found that the parameterized models with cylinder diameter of $0.5 \mathrm{~cm}$ (i.e. models A2, B2 and $\mathrm{C} 2$ ) had comparable hydraulic resistance to the "real" counterparts (Husrin, 2012).

\section{Laboratory experiments on tsunami attenuation by mangrove forest}

\subsection{Bore generation system in a twin-wave flume}

In order to reproduce more realistically the flooding conditions of a vegetated area by a tsunami in the laboratory, a bore generator was constructed in the twin-wave flume of the LWI
(Leichtweiß-Institute for Hydraulic Engineering and Water Resources). It consists of two bore gates installed in the $2 \mathrm{~m}$ - and $1 \mathrm{~m}$-wide flumes at a distance of $20 \mathrm{~m}$ from a wave maker. The bore gates can be operated synchronically or individually by means of a pneumatic system shown in Fig. 4a. The bore gate in the $1 \mathrm{~m}$-wide flume is equipped with three pneumatic cylinders (with maximum operating pressure of 10 bar), while two larger cylinders (with maximum operating pressure of 12 bar) were required for operating the heavier bore gate in the $2 \mathrm{~m}$-wide flume. The non-moveable frames of the gates are fixed to the flume bottom and flume walls and allow for opening of the movable parts of the gates by swinging around a horizontal axis. The moveable parts of the bore gates are covered by plywood plates and are equipped with additional weight to increase the swinging moment. A weight control is installed at the seaward side of the bore generators to provide a support for the gates after their opening, so that the stored water can flow out undisturbed. Isolation of the gate frames by means of rubber stripes and silicon layers was required to prevent from water leakage towards the lee-side of the gates. 
Table 3. Locations of force transducers measuring forces exerted on single mangrove models (FTS1-FTS10) within forest models of different widths (symbols T6-T244 denote the number of the parameterized mangrove model, to which the force transducer was connected - see also Fig. 6).

\begin{tabular}{|c|c|c|c|c|c|c|c|c|c|c|}
\hline \multicolumn{11}{|c|}{ Experiments with solitary waves } \\
\hline & FTS1 & FTS2 & FTS3 & FTS4 & FTS5 & FTS6 & FTS7 & FTS8 & FTS9 & FTS10 \\
\hline$B=0.75 \mathrm{~m}$ & $\mathrm{~T} 10$ & T35 & T60 & T6 & T31 & T56 & T3 & $\mathrm{T} 28$ & T53 & - \\
\hline$B=1.5 \mathrm{~m}$ & T6 & $\mathrm{T} 7$ & $\mathrm{~T} 31$ & T56 & T68 & T69 & T81 & T106 & $\mathrm{T} 118$ & $\mathrm{~T} 119$ \\
\hline$B=2.25 \mathrm{~m}$ & T6 & $\mathrm{T} 7$ & $\mathrm{~T} 31$ & T56 & T106 & $\mathrm{T} 118$ & $\mathrm{~T} 119$ & $\mathrm{~T} 168$ & T169 & $\mathrm{T} 161$ \\
\hline$B=3.0 \mathrm{~m}$ & T6 & T56 & T106 & $\mathrm{T} 118$ & $\mathrm{~T} 119$ & T168 & T169 & $\mathrm{T} 181$ & T206 & $\mathrm{T} 243$ \\
\hline \multicolumn{11}{|c|}{ Experiments with tsunami bores } \\
\hline & FTS1 & FTS2 & FTS3 & FTS4 & FTS5 & FTS6 & FTS7 & FTS8 & FTS9 & FTS10 \\
\hline$B=0.75 \mathrm{~m}$ & T6 & $\mathrm{T} 7$ & T19 & $\mathrm{T} 31$ & $\mathrm{~T} 44$ & T56 & T57 & T119 & T181 & $\mathrm{T} 244$ \\
\hline$B=1.5 \mathrm{~m}$ & T6 & $\mathrm{T} 7$ & $\mathrm{~T} 31$ & T56 & T81 & T106 & $\mathrm{T} 118$ & T119 & $\mathrm{T} 181$ & $\mathrm{~T} 244$ \\
\hline$B=2.25 \mathrm{~m}$ & - & - & - & - & - & - & - & - & - & - \\
\hline$B=3.0 \mathrm{~m}$ & T6 & $\mathrm{T} 7$ & T56 & $\mathrm{T} 81$ & $\mathrm{~T} 119$ & $\mathrm{~T} 156$ & $\mathrm{~T} 181$ & T206 & $\mathrm{T} 243$ & $\mathrm{~T} 244$ \\
\hline
\end{tabular}

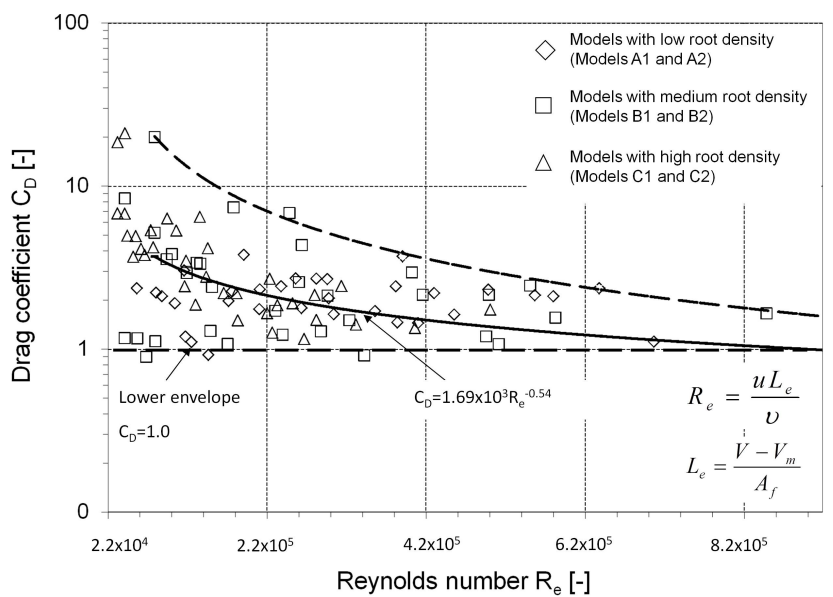

Fig. 3. Drag coefficient versus Reynolds number for the tests in quasi-steady flow flume (data corresponding to the "real mangrove models" A1, B1, C1 and the parameterized mangrove models A2, $\mathrm{B} 2, \mathrm{C} 2$ is considered only).

\subsection{Experimental set-up and programme}

The experiments on tsunami attenuation by mangrove forest were performed at a scale of $1: 25$ (according to the Froude similitude law) in the $2 \mathrm{~m}$-wide wave flume of the LWI, which is approximately $1.25 \mathrm{~m}$ high and $90 \mathrm{~m}$ long (Fig. 5). The mangrove forest model was integrated into a beach model made of plywood. The beach model consisted of a foreshore part with a length of ca. $8.3 \mathrm{~m}$ and a slope of ca. $1: 20$, evolving into a horizontal platform of height of $0.415 \mathrm{~m}$ (Fig. 5a). This elevation of the forest model at a certain level above the flume bottom was necessary for the installation of the force transducers to measure the forces exerted on single tree models and the entire forest (see Sect. 3.3).
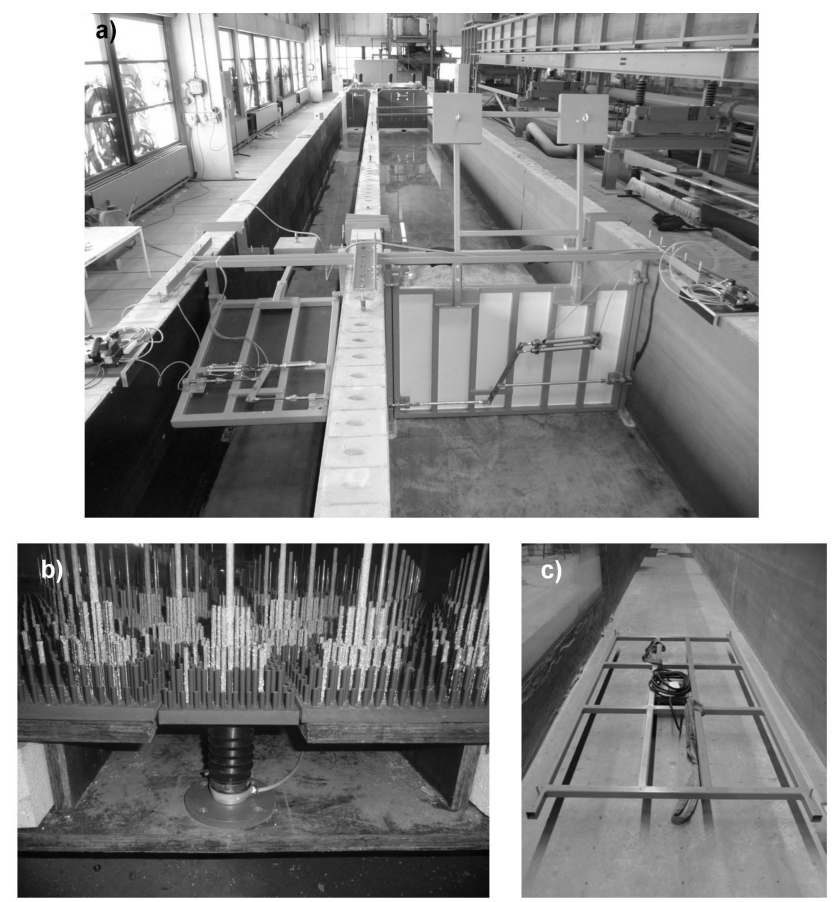

Fig. 4. Bore gates installed in the twin-wave flume of the LWI (a), force transducer connected to a single mangrove tree model, measuring wave-induced forces (b), force transducer measuring waveinduced forces exerted on entire forest model (c).

The forest model was composed of the parameterized mangrove models A2, arranged in shifted rows with 12 and 13 single trees, respectively, as shown in Fig. 6. Only one forest density (ca. 44 trees $\mathrm{m}^{-2}$ ), corresponding to the highest forest density possible by considering the tree model dimensions, was tested for different forest widths. This resulted in a total of 62 tree models for forest width $B=0.75 \mathrm{~m}, 125$ tree models for $B=1.5 \mathrm{~m}, 187$ tree models for $B=2.25 \mathrm{~m}$ 


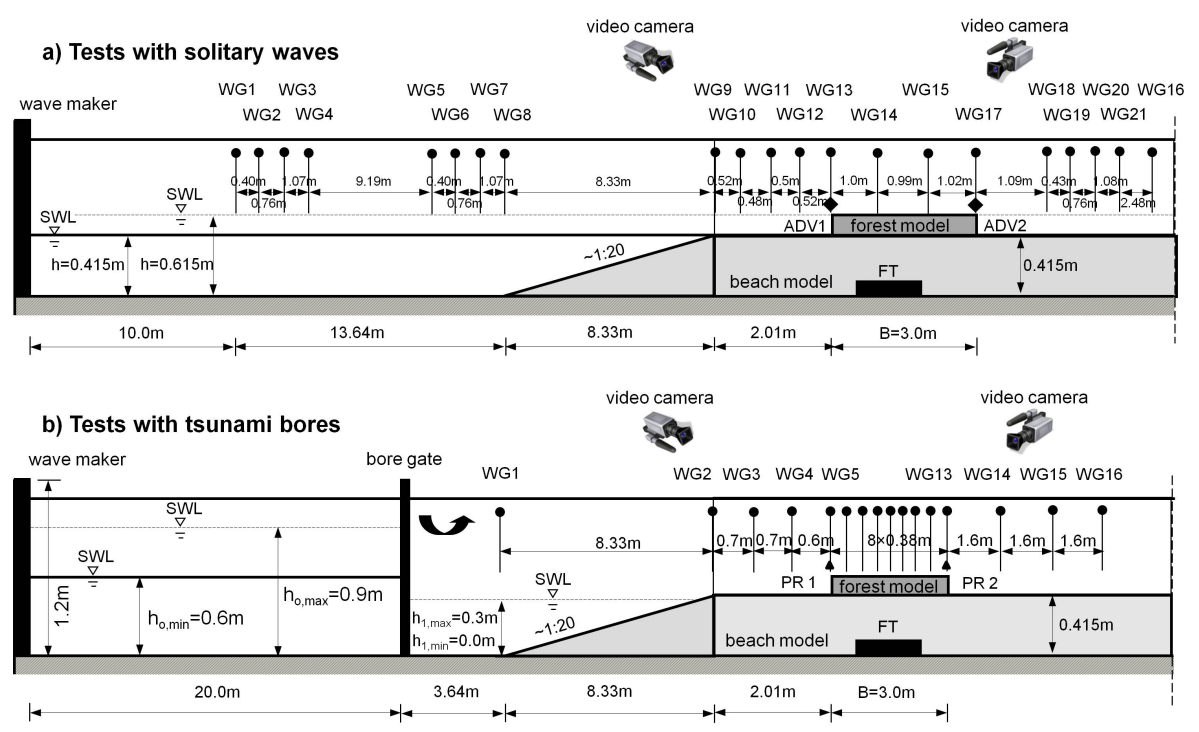

c) Construction of beach model

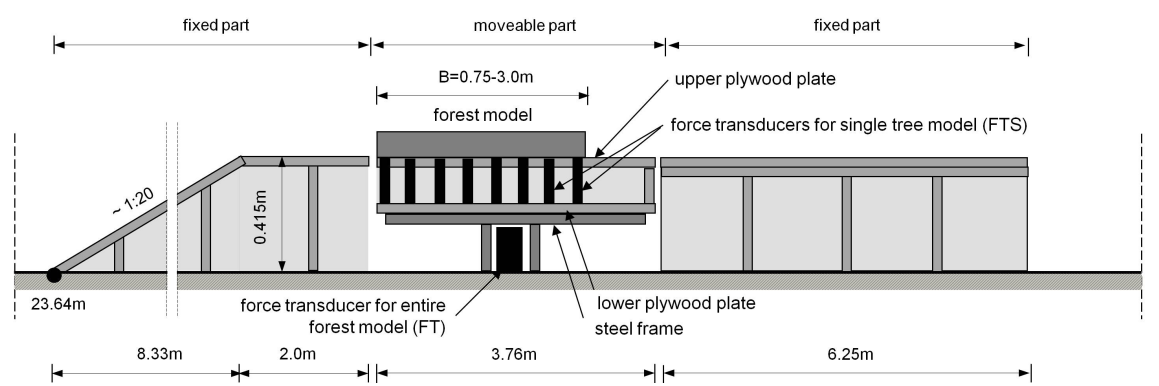

Fig. 5. A schematic view of exemplary experimental model set-up with forest model of width of $B=3.0 \mathrm{~m}$ : (a) in experiments with solitary waves, (b) in experiments with tsunami bores, (c) construction details of beach model (ADV - acoustic Doppler velocimeter, FT - transducer measuring forces exerted on entire forest, FTS - transducer measuring forces exerted on single mangrove model, PR - micro-propeller-type current meter, WG - wave gauge). Arrangement of force transducers measuring forces exerted on single tree models is provided in Fig. 6 and Table 3.

(investigated solely in the tests with solitary waves) and 250 tree models for $B=3.0 \mathrm{~m}$.

Solitary waves of different incident nominal wave height $H_{\mathrm{i}, \text { nom }}=0.04-0.2 \mathrm{~m}$ (with an interval of $0.04 \mathrm{~m}$ ) were generated at different water depths, ranging from $h=0.415 \mathrm{~m}$ (tree models fully emerged) to $h=0.615 \mathrm{~m}$ (tree models fully submerged, i.e. up to the top of the trunk) with an interval of $0.05 \mathrm{~m}$. The lowest water level was however excluded from the experimental programme in further tests, since no wave transmission through the forest model was observed.

In order to account for a wide range of initial bore conditions, different water levels behind the bore gate $\left(h_{0}=0.6\right.$, $0.7,0.8$ and $0.9 \mathrm{~m}$ ) were used in the tests, corresponding to the volume of the stored water of $V_{\mathrm{w}}=24,28,32$ and $36 \mathrm{~m}^{3}$. For each water level behind the bore gate, bore propagation over a wet bed (with water level in front of the bore gate $h_{1}=0.1,0.2$ and $0.3 \mathrm{~m}$ ) and a dry bed (with $h_{1}=0.0 \mathrm{~m}$ ) was investigated (see Fig. 5b).

\subsection{Applied measuring and observation techniques}

Forces resulting from the tsunami interaction with the single tree models were measured by 10 FTS transducers of maximum load of $60 \mathrm{~N}$. The transducers were mounted to the bottom part of the mangrove models and distributed over the entire forest width to provide the pattern of force reduction (see Figs. 4b, 5c and Table 3). The wave-induced forces exerted on the entire forest model were measured by means of a second type of the force transducer (FT), developed in a collaboration with Hottinger Baldwin Messtechnik GmbH (Fig. 4c). The transducer is capable of measuring horizontal lateral forces up to $5 \mathrm{kN}$, under submergence of maximum $5 \mathrm{~m}$ in water temperature range from $10^{\circ} \mathrm{C}$ to $40^{\circ} \mathrm{C}$. Moreover, it can also measure axial force up to $5 \mathrm{kN}$ and torsion moment up to $2 \mathrm{kNm}$. The bottom part of the transducer was fixed to the bottom of the $2 \mathrm{~m}$-wide flume, at a distance of $35.86 \mathrm{~m}$ from the wave maker, in the middle of the flume width. A special construction of the horizontal part of the 


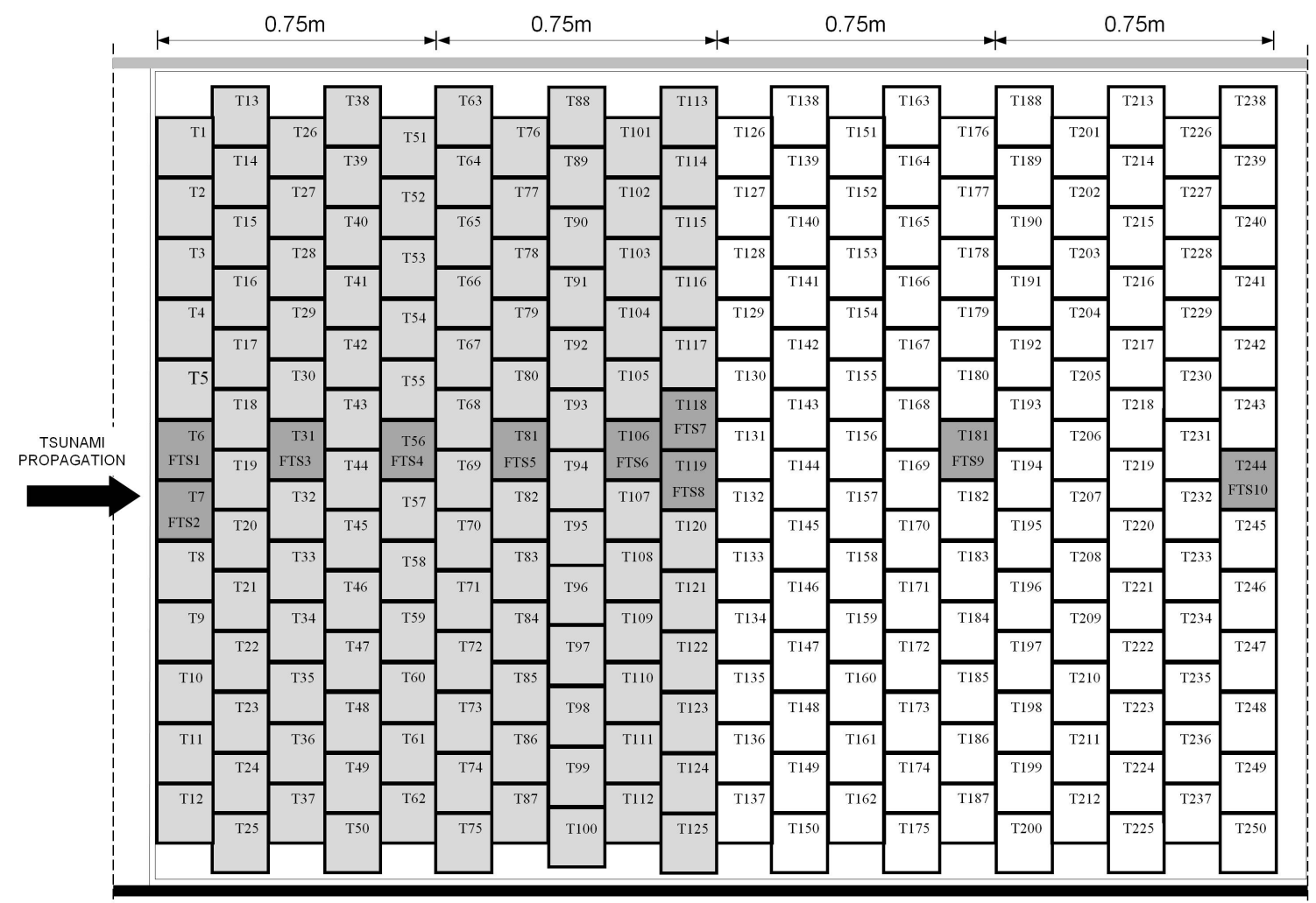

Fig. 6. Arrangement of force transducers measuring forces exerted on single tree models (FTS1-FTS10), exemplarily for tests with a bore and forest width $B=1.5 \mathrm{~m}$ (symbols T1-T250 denote the number of the parameterized mangrove tree models, light grey colour indicates mangrove models constituting forest model of a given width, dark grey colour indicates tree models connected to force transducers FTS).

beach model was required to transfer the forces exerted on the forest model to the force transducer as shown in Fig. 5c. Gaps between flume walls and the moveable part of the beach model allowed for free motion of the entire measuring platform. In the tests with solitary waves, the force transducers were arranged solely along the forest model (Fig. 11 and Table 3), while in the tests with tsunami bores both along and behind the forest (i.e. over a distance equal the maximum examined forest width of $B=3.0 \mathrm{~m}$ ), as indicated in Fig. 12 and Table 3. The latter arrangement allowed to compare the force envelope irrespective of the examined forest width.

Water free surface elevation was measured in front of, in and behind the forest model, by 21 and 16 wave gauges (WG) in the tests with solitary waves and tsunami bores, respectively (Fig. 5a, b).

Flow velocity under a solitary wave was recorded by two acoustic Doppler velocimeters installed at the beginning and the end of the forest model (ADV1 and ADV2, respectively). The bottom of all sensors was at a height of $0.1 \mathrm{~m}$ above the beach model. Bore velocity was measured by two propellertype current meters, installed at a height of $5 \mathrm{~cm}$ above the beach platform, ca. $0.04 \mathrm{~m}$ in front of and behind the forest model (PR1 and PR2, respectively) (Fig. 5b).
Wave propagation through the forest was recorded by video cameras installed at the beginning and at the end of the forest model (Fig. 5a, b).

\section{Tsunami propagation through the forest model}

\subsection{Classification of observed propagation modes of solitary waves and tsunami bores}

Classification of the observed wave and bore propagation modes enabled to identify the source of wave and bore damping (i.e. by the forest model or by the combination of the foreshore topography and the forest model), and thus, to properly determine the effectiveness of the mangroves to attenuate tsunami. The wave and bore evolution modes were classified by means of the water surface elevation measured by wave gauges as well as by video analysis.

\subsubsection{Solitary wave evolution modes}

Several aspects, such as the location of the incipient wave breaking and the generation of wave fission, were considered in the determination of the following five solitary wave evolution modes. 


\section{Non-breaking waves (contribution of the forest model to wave attenuation)}

Non-breaking incident waves disintegrating into solitons (evolution mode EMI). A solitary wave train, consisting of waves of decreasing height (solitons), was generated as a result of the wave fission process due to the change of the water depth, from $h=0.465-0.615 \mathrm{~m}$ in front of the beach model to $d_{\mathrm{r}}=0.05-0.20 \mathrm{~m}$ over the beach model (Fig. 7a). This mode was typical of waves of smaller nominal incident heights: $H_{\mathrm{i}, \text { nom }}=0.04 \mathrm{~m}$ generated at water depth $h=0.515-0.615 \mathrm{~m}$ and $H_{\mathrm{i}, \text { nom }}=0.08 \mathrm{~m}$ for $h=0.615 \mathrm{~m}$.

\section{Breaking waves (contribution of the forest model and the foreshore topography to wave attenuation)}

- Waves breaking over the beach slope (region 1) and disintegrating into solitons (evolution mode EM2), as shown in Fig. 7b. This evolution mode was observed for waves of medium and largest height $\left(H_{\mathrm{i}, \text { nom }}=0.12-0.20 \mathrm{~m}\right)$, propagating in the smallest examined water depth of $h=0.465 \mathrm{~m}$.

- Waves breaking between the end of the beach slope and the beginning of the forest model (region 2) and disintegrating into solitons (evolution mode EM3). Two submodes can be further distinguished depending on the order of generation of the breaking and fission processes (Fig. 7c): (i) generation of wave breaking followed by wave disintegration into solitons (observed in cases, where the inception point of the breaking event was located very close to the end of the beach slope), (ii) generation of wave fission followed by wave breaking and a further development of wave disintegration (observed in cases, where the inception point of the breaking event was located close to the beginning of the forest model). This evolution mode was the most common pattern of wave behaviour observed in this study.

- Waves breaking in the forest model (region 3) and disintegrating into solitons (evolution mode EM4). As a result of the fission process, induced in front of the forest model, the height of the leading solitary wave increased till the wave became unstable and broke in the forest model. A further development of the solitary wave train was clearly seen once the process of wave breaking was accomplished (Fig. 7d). This evolution mode occurred for waves of medium height of $H_{\mathrm{i}, \text { nom }}=0.08-0.16 \mathrm{~m}$, generated at the highest water levels of $h=0.565$ and $0.615 \mathrm{~m}$ and propagating through the forest model of width $B=1.50-3.0 \mathrm{~m}$.

- Waves breaking behind the forest model (in region 4) and disintegrating into solitons (evolution mode EM5). The characteristic of this evolution mode is similar to that of the evolution mode EM4 (Fig. 7e). It occurred, however, for waves of height of $H_{\mathrm{i}, \text { nom }}=0.08 \mathrm{~m}$, generated at a water depth of $h=0.565 \mathrm{~m}$, as well as $H_{\mathrm{i}, \text { nom }}=0.12 \mathrm{~m}$ generated at a water depth of $h=0.615 \mathrm{~m}$, propagating through the forest of the narrowest width $B=0.75 \mathrm{~m}$.

The solitary wave evolution modes were found to be dependent predominantly on the incident wave height and the water depth. The forest width plays an important role when distinguishing between wave breaking in and behind the forest model. For instance, waves, which broke behind the narrowest forest model $(B=0.75 \mathrm{~m})$, broke in the forest model for larger forest widths $(B=1.25-3.0 \mathrm{~m})$.

\subsubsection{Tsunami bore evolution modes}

A bore with a turbulent front was generated in each test, irrespective of the water depth conditions in front of and behind the bore gate. The bore height, as well as the intensity of the turbulence at the bore front, varied however with the water levels $h_{\mathrm{o}}$ and $h_{1}$. The weakest bores, not reaching the end of a forest model, were generally observed for the smallest water depth behind the bore gate $\left(h_{\mathrm{o}}=0.6 \mathrm{~m}\right)$ and the two widest forest widths $(B=1.5$ and $3.0 \mathrm{~m})$. In contrast to the experiments with the solitary waves, the profile of the bore approaching the forest model was strongly modified by the water accumulation within the first three tree rows (Fig. 8), described in more detail in Sect. 4.2.2.

\subsection{Wave and bore height envelopes}

\subsubsection{Envelope of solitary wave height}

The heights of the solitary waves, generated in the deeper water in front of the beach model, were $H_{\mathrm{i} \text {, gen }}=0.04,0.082$, $0.125,0.168$, and $0.21 \mathrm{~m}$. The latter were obtained by averaging the maximum wave heights in all tests with the same incident wave conditions. The generated wave heights are almost identical to the incident nominal wave heights $H_{\mathrm{i} \text {, nom }}=0.04$, $0.08,0.12,0.16$ and $0.2 \mathrm{~m}$. The wave heights remained constant during wave propagation over the horizontal part of the wave flume, which preceded the beach model with the integrated forest model. Once the waves ran onto the beach model, their height was modified by the combined processes of wave shoaling, wave breaking, wave reflection and wave fission, according to the corresponding evolution mode.

The height of the non-breaking waves (EM1) increased slightly in front of the forest model to less than $0.05 \mathrm{~m}$ and $0.10 \mathrm{~m}$ for $H_{\mathrm{i}, \text { nom }}=0.04$ and $0.08 \mathrm{~m}$, respectively. This was primarily due to wave shoaling occurring over the foreshore beach slope and further due to the generation of the fission process, resulting from the water depth reduction over the horizontal part of the beach model (Figs. 7a and 9a). The amplification of the height of the leading wave (i.e. the first soliton) accompanied the first stage of the fission process, in 

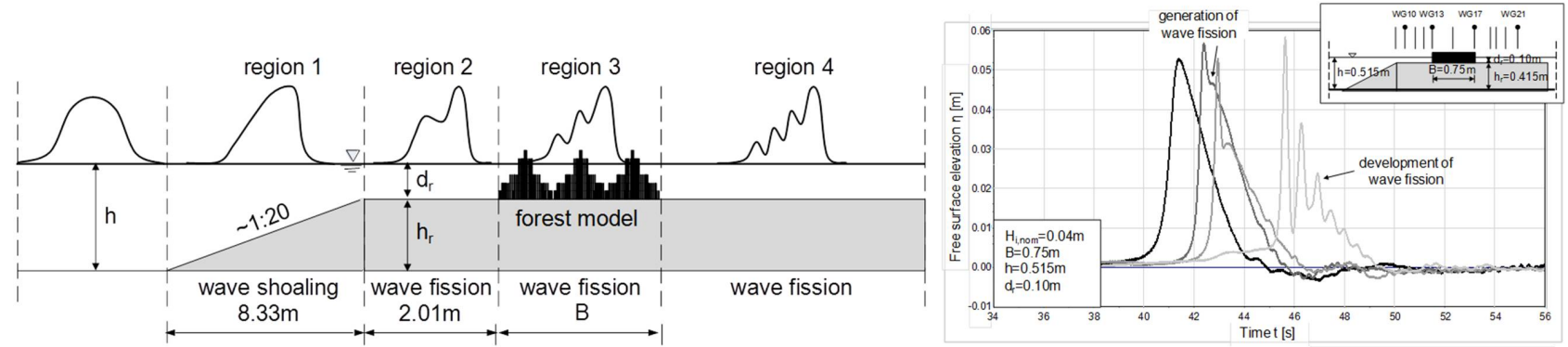

b) Waves breaking over beach slope (EM2)
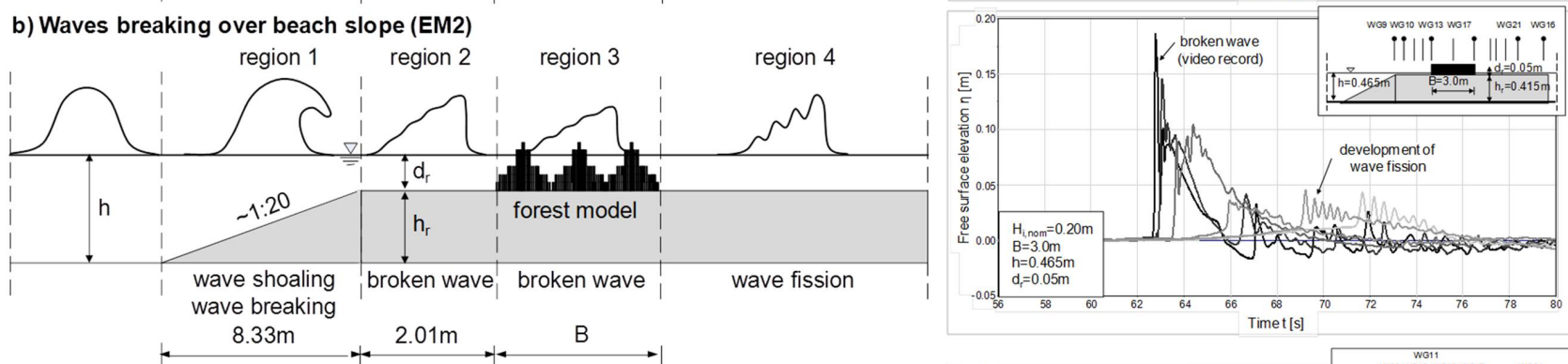

c) Waves breaking in front of forest model (EM3)


EM3a: wave breaking
EM3b: wave fission and wave breaking

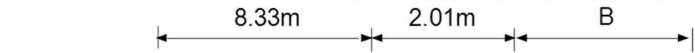

d) Waves breaking in forest model (EM4)
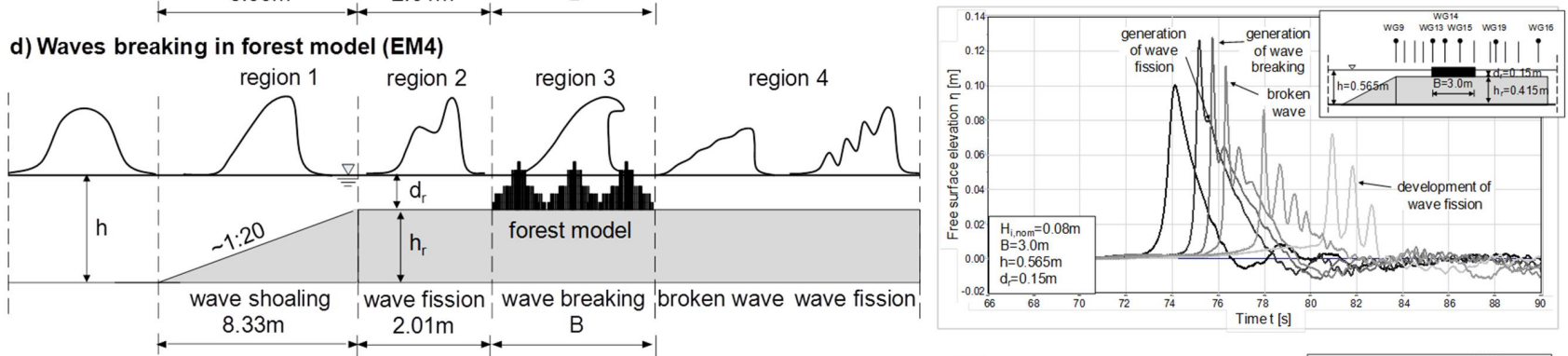

e) Waves breaking behind forest model (EM5)


Fig. 7. Observed modes of solitary wave evolution in the foreshore and in the mangrove forest for different forest widths $B$, incident wave heights $H_{\mathrm{i} \text {, nom }}$ and water depths $h$ and $d_{\mathrm{r}}$ in the far field and just in front of the forest, respectively. 
a) Bore approaching the forest model
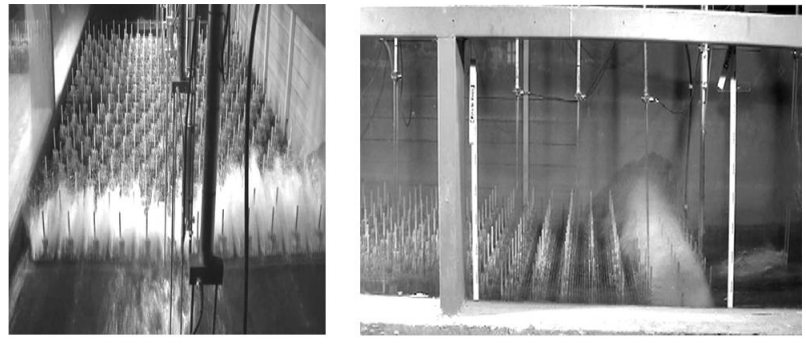

b) Water accumulation in first three tree rows
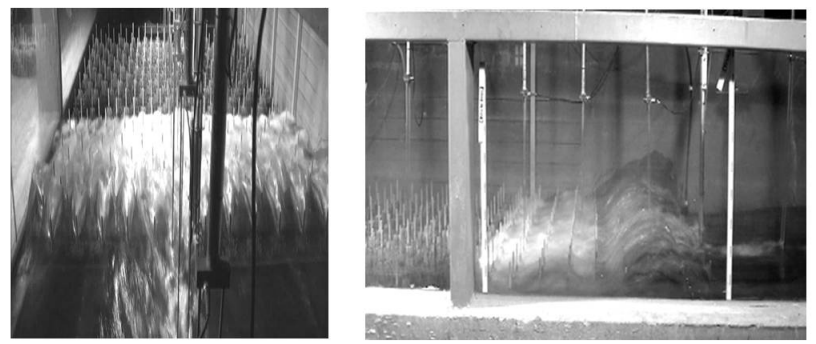

c) Bore propagation through the forest model and generation of wave reflected from the forest model
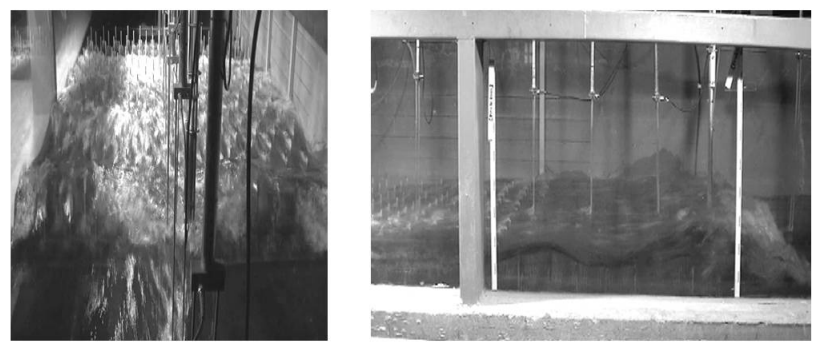

d) Quasi-constant flow depth conditions
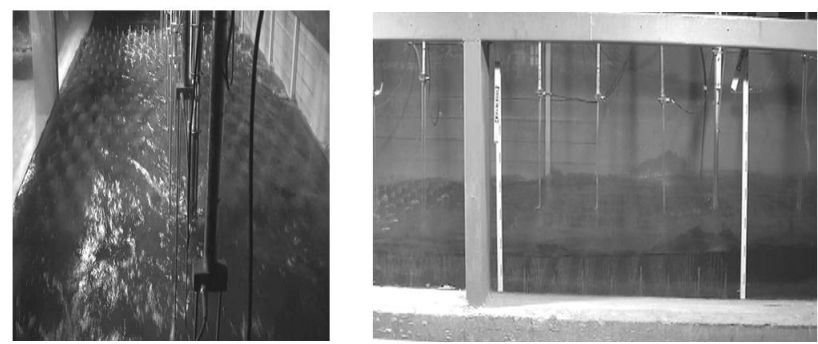

Fig. 8. Selected snapshots of tsunami bore propagation through forest model of width $B=3.0 \mathrm{~m}$ (water depth behind bore gate $h_{\mathrm{o}}=0.8 \mathrm{~m}$, water depth in front of bore gate $h_{1}=0.3 \mathrm{~m}$ ).

which humps, representing the successive solitons, emerged at the rear part of the leading wave. As the wave disintegration into solitons developed, the height of the leading soliton decreased. In the forest model, the wave height decreased as a result of higher wave energy losses due to the presence of the tree models (mangrove roots). The rate of this wave height reduction was clearly higher for lower water depths and wider forests; under these conditions the wave interaction with the
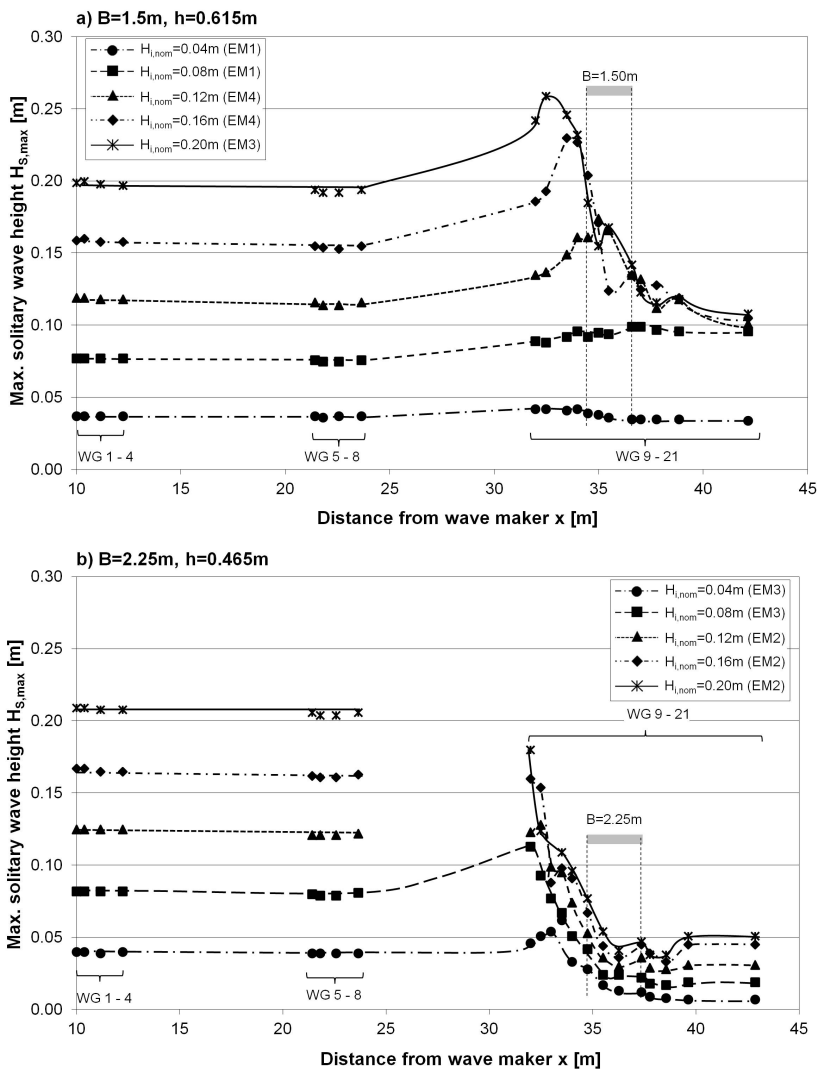

Fig. 9. Selected envelopes of solitary wave height: (a) in case of forest width $B=1.5 \mathrm{~m}$ and water depth $h=0.615 \mathrm{~m}$, (b) in case of forest width $B=2.25 \mathrm{~m}$ and water depth $h=0.465 \mathrm{~m}$ (see also Fig. 7 for wave evolution modes and Fig. 5a for wave gauge locations).

roots was stronger due to the partial root emergence and the longer propagation distance over the region of higher roughness. Exemplarily, waves of $H_{\mathrm{i}, \text { nom }}=0.04 \mathrm{~m}$, propagating in water depth of $h=0.565$ and $0.615 \mathrm{~m}$ through the forest model of width $B=0.75$ and $1.5 \mathrm{~m}$, became slightly smaller than $0.04 \mathrm{~m}$ behind the forest (Fig. 9a), while the height of the same wave propagating in $h=0.515 \mathrm{~m}$ through the forest of $B=3.0 \mathrm{~m}$ became ca. $0.02 \mathrm{~m}$ high. A successive increase of the height of waves of $H_{\mathrm{i}, \text { nom }}=0.08 \mathrm{~m}$ up to ca. $0.10 \mathrm{~m}$, as a result of the fission process, was observed behind the two narrowest forest models $(B=0.75$ and $1.5 \mathrm{~m})$ and water depth $h=0.615 \mathrm{~m}$ (Fig. 9a). In contrast, the height of the same incident waves was reduced approximately to the value of the wave height reached in front of the forest model during propagation over wider forest models $(B=2.25$ and $3.0 \mathrm{~m}$ ).

The height of waves classified as evolution mode EM2 was reduced significantly already over the beach slope due to the induced wave breaking process (Figs. $7 b$ and $9 b$ ). Due to the limited number of deployed wave gauges, it was not possible to record wave heights over the foreshore beach slope. Therefore, the wave height envelope for this evolution mode is not complete between wave gauges WG8 and WG9 in Fig. 14b. 
However, it is assumed that the wave shoaled over the foreshore slope until it became unstable and broke. At the end of the beach slope, the wave heights decreased to ca. 0.12, 0.16 and $0.18 \mathrm{~m}$ for $H_{\mathrm{i} \text {, nom }}=0.12,0.16$ and $0.2 \mathrm{~m}$ at water depth $h=0.465 \mathrm{~m}$, respectively. They diminished further to ca. $0.03,0.04$ and $0.05 \mathrm{~m}$, respectively, as the broken waves propagated through the forest model.

Generally, waves of evolution mode EM3 reached their maximum height, at breaking, in front of the forest model, where they eventually broke. Further wave height amplification was caused by the generation of the solitons in this region (Figs. 7c and 9a, b). Only in few cases, the maximum wave height occurred at the transition point between the beach slope and the horizontal part of the beach (i.e. at wave gauge WG9). The wave height, at breaking, was primarily determined by the water depth and it increased with the increasing submergence of the mangrove models. Exemplarily, the height at breaking of waves of $H_{\mathrm{i} \text {, nom }}=0.12 \mathrm{~m}$ was ca. $0.17 \mathrm{~m}$ for $h=0.515 \mathrm{~m}$, while it increased up to ca. $0.2 \mathrm{~m}$ for $h=0.565 \mathrm{~m}$. A strong reduction of the wave height accompanied the propagation of the broken wave through the forest, exemplarily to ca. $0.01 \mathrm{~m}$ for $H_{\mathrm{i}, \text { nom }}=0.04 \mathrm{~m}$ and to ca. $0.02 \mathrm{~m}$ for $H_{\mathrm{i}, \text { nom }}=0.08 \mathrm{~m}$ (Figs. $9 \mathrm{a}, \mathrm{b}$ ). A further development of the fission was not suppressed by the breaking event and thus a slight increase of the height of the leading wave was noticeable.

For waves breaking within the forest (EM4), the wave height increased in front of the forest model and partly in the forest, irrespective of the generated wave height: waves reached ca. $0.11,0.13$ and $0.18 \mathrm{~m}$ at the end of the beach slope for $H_{\mathrm{i}, \text { nom }}=0.08 \mathrm{~m}$ at $h=0.565 \mathrm{~m}$ and $H_{\mathrm{i}, \text { nom }}=0.12$, $0.16 \mathrm{~m}$ at $h=0.615 \mathrm{~m}$, respectively (Figs. $5 \mathrm{~d}$ and $9 \mathrm{a}$ ). A further wave amplification up to the maximum wave height, at breaking, in the forest up to ca. $0.13,0.17$ and $0.23 \mathrm{~m}$, respectively, resulted from the development of the fission process. The wave height reduction within the measured propagation distance, associated with the breaking event, was weaker for $H_{\mathrm{i} \text {, nom }}=0.08$ and $0.12 \mathrm{~m}$ - the wave heights behind the forest model approached approximately the value of the nominal incident wave heights $\left(H_{\mathrm{i}, \text { nom }}\right)$. Only for $H_{\mathrm{i}, \text { nom }}=0.16 \mathrm{~m}$, the reduction rate was much higher, and in this case the wave height behind the forest decreased below the value of the nominal incident wave height (up to ca. $0.11 \mathrm{~m}$ ).

A similar pattern of the wave height envelope was observed for waves breaking behind the forest (EM5) as illustrated in Fig. 5e. Exemplarily, for $H_{\mathrm{i}, \text { nom }}=0.08 \mathrm{~m}$ the wave height at the end of the beach slope was ca. $0.12 \mathrm{~m}$ and it was amplified through the phenomenon of wave disintegration into solitons up to ca. $0.14 \mathrm{~m}$ at the end of the forest model. The wave became unstable and broke behind the forest with the minimum measured height of ca. $0.09 \mathrm{~m}$.

\subsubsection{Envelope of tsunami bore height}

The bore, generated after a sudden opening of the bore gate, rushed onto the sloping part of the beach, reaching a maximum height of $H_{\mathrm{b}, \max } \sim 0.09,0.13,0.17,0.22 \mathrm{~m}$ for water depth behind the bore gate $h_{\mathrm{o}}=0.6-0.9 \mathrm{~m}$, respectively (independent of water depth in front of the bore gate $h_{1}=0.0-0.3 \mathrm{~m}$ ), at wave gauge WG2 placed at the end of the slope. The incident bore height was then reduced by the accompanying turbulence effects to $H_{\mathrm{b}, \max } \sim 0.04,0.08,0.12$, and $0.15 \mathrm{~m}$ at wave gauge WG4. Due to the presence of the mangrove models, the incident bore front increased in height approximately in the first three rows of the forest, resulting in a water impoundment reaching the top of the mangrove trunks $(20 \mathrm{~cm})$ and more. This was accompanied by very strong turbulent processes as shown in Fig. 8a and b. The bore front behind the first three tree rows was first significantly reduced to a thin water layer reaching approximately up to half of the trunk height. Once the bore front reached the middle of the forest model, the water level in the forest model increased and a wave reflected from the frontal forest row was generated (Fig. 8c). Finally, the flow depth over the entire forest model became constant, equal to the height of the mangrove trunks (Fig. 8d).

The bore height envelope was found to be predominantly dependent on the water depth behind the bore gate - the bore height along the entire beach model became larger as $h_{\mathrm{o}}$ increased (Förstner, 2010; Geiling, 2011a, b). In contrast, the influence of the water depth in front of the bore gate on the bore evolution is almost negligible.

The spatial distribution of the maximum incident bore height is plotted exemplarily for $h_{\mathrm{o}}=0.8 \mathrm{~m}$ and $h_{1}=0.0 \mathrm{~m}$ in Fig. 10a. The bore height in front of the forest (at wave gauges WG2-WG4) was of the same order for all considered forest widths. This indicates a very good repeatability of the incident bore conditions in the performed experiments. Due to the turbulent nature of the generated bore, the bore height decreased within the distance between WG2 and WG4. A very strong and sudden amplification of the bore height (up to a factor of 2.5) took place at the beginning of the forest (wave gauge WG5) and was the strongest for the widest forest (i.e. $B=3.0 \mathrm{~m}$ ). This was caused by a partial blockage of the bore by the very dense mangrove root system, leading to the above mentioned water accumulation (set-up) in front of and within the forest model (up to the three first tree rows).

The amplified bore height was significantly decreased along the forest model as a result of the turbulent bore interaction with the mangrove roots. The bore height at the end of the forest (i.e. at WG7 for $B=0.75 \mathrm{~m}$, WG9 for $B=1.5 \mathrm{~m}$ and WG13 for $B=3.0 \mathrm{~m}$ ) tended to be of approximately the same order for the two smallest forest widths $B=0.75$ and $1.5 \mathrm{~m}$ : ca. $0.07 \mathrm{~m}$ for $h_{\mathrm{o}}=0.7 \mathrm{~m}$, ca. $0.1 \mathrm{~m}$ for $h_{\mathrm{o}}=0.8 \mathrm{~m}$ and ca. $0.14 \mathrm{~m}$ for $h_{\mathrm{o}}=0.9 \mathrm{~m}$ (see Fig. 10a). In contrast, the bore height at the end of the forest of width $B=3.0 \mathrm{~m}$ was lower by about $2-3 \mathrm{~cm}$ and yielded $0.03 \mathrm{~m}$ for $h_{\mathrm{o}}=0.7 \mathrm{~m}$, 

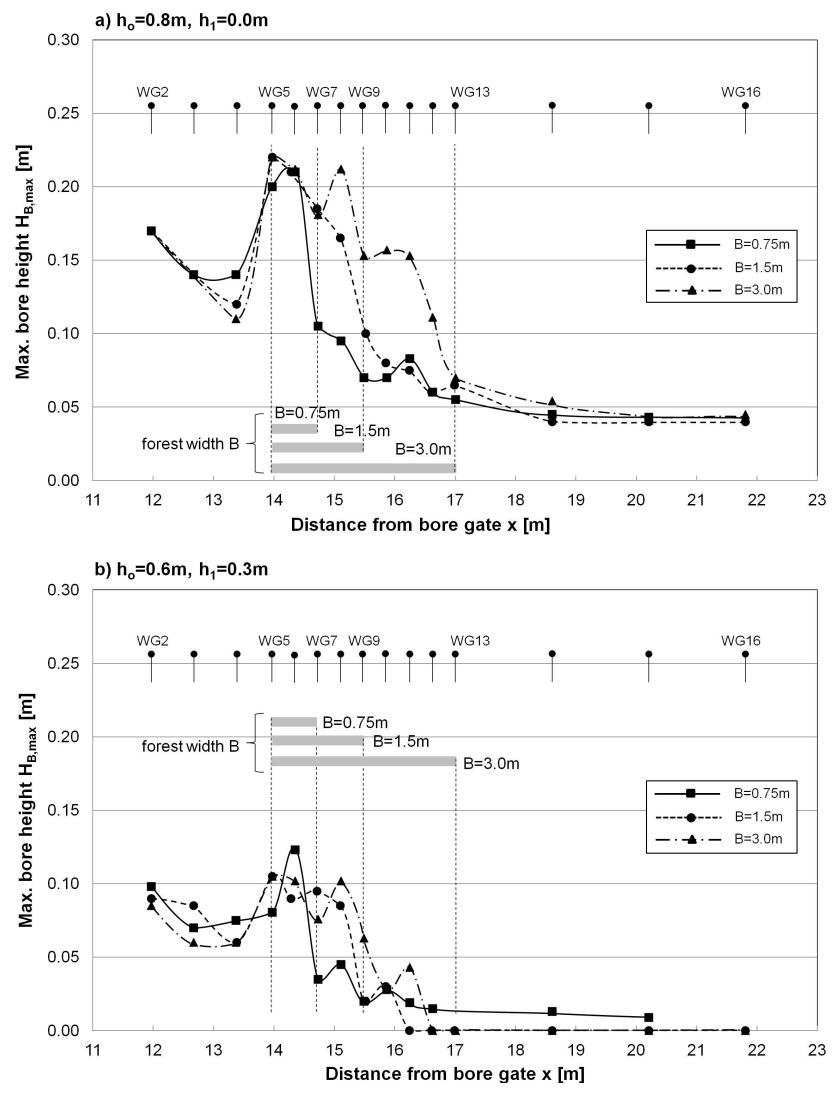

Fig. 10. Selected envelopes of bore height: (a) water depth behind bore gate $h_{\mathrm{o}}=0.8 \mathrm{~m}$ and water depth in front of bore gate $h_{1}=0 \mathrm{~m}$, (b) water depth behind bore gate $h_{\mathrm{o}}=0.6 \mathrm{~m}$ and water depth in front of bore gate $h_{1}=0.3 \mathrm{~m}$.

ca. $0.07 \mathrm{~m}$ for $h_{\mathrm{o}}=0.8 \mathrm{~m}$ and ca. $0.12 \mathrm{~m}$ for $h_{\mathrm{o}}=0.9 \mathrm{~m}$. The difference between the bore heights at the forest end became slightly larger for the tests with $h_{\mathrm{o}}=0.6 \mathrm{~m}$, where the bore height was ca. $0.04 \mathrm{~m}$ for $B=0.75 \mathrm{~m}, 0.02 \mathrm{~m}$ for $B=1.5 \mathrm{~m}$ and $0 \mathrm{~m}$ (no transmission) for $B=3.0 \mathrm{~m}$ (Fig. 10b).

A further bore height reduction, however not as large as along the forest model, took place behind the forest until reaching a constant value irrespective of forest width: ca. $0.03 \mathrm{~m}$ for $h_{\mathrm{o}}=0.7 \mathrm{~m}, 0.04 \mathrm{~m}$ for $h_{\mathrm{o}}=0.8 \mathrm{~m}$ and $0.07 \mathrm{~m}$ for $h_{\mathrm{o}}=0.9 \mathrm{~m}$. In the case of the lowest water depth behind the bore gate $\left(h_{\mathrm{o}}=0.6 \mathrm{~m}\right)$, transmitted bore height of ca. $0.01 \mathrm{~m}$ was measured solely for the shortest forest width of $B=0.75 \mathrm{~m}$.

\subsection{Forces induced by waves and bores on single trees in the mangrove forest}

\subsubsection{Envelope of forces exerted by solitary waves on single mangrove models}

The magnitude of the forces exerted by waves on single mangrove models was influenced primarily by the wave evolution modes (governed by the water depth and the incident
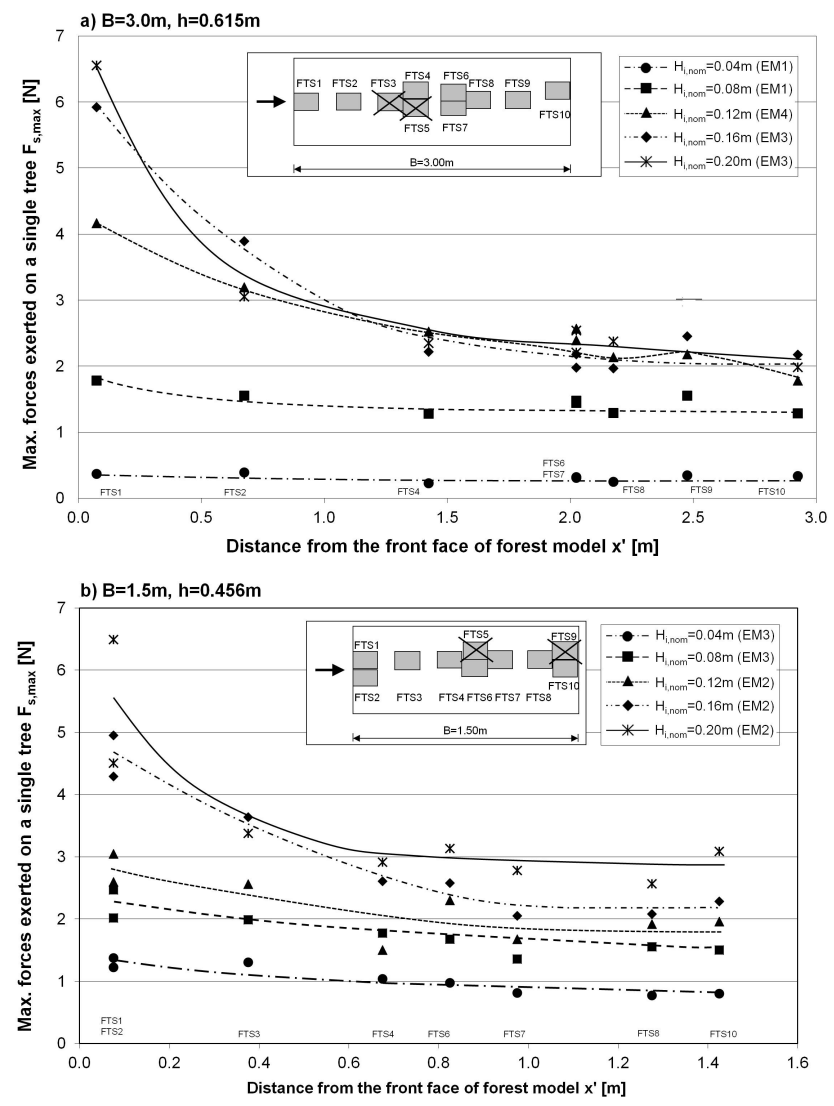

Fig. 11. Exemplary envelope of forces exerted by solitary waves on single mangrove tree models: (a) in case of forest width $B=3.0 \mathrm{~m}$ and water depth $h=0.465 \mathrm{~m}$, (b) in case of forest width $B=1.5 \mathrm{~m}$ and water depth $h=0.465 \mathrm{~m}$ (see Fig. 6 and Table 3 for force transducer locations).

wave height conditions). The highest forces were always recorded in the first tree row and their magnitude was independent of the forest width. For a given evolution mode, these forces became larger with the increasing incident nominal wave height. For identical evolution modes and incident wave heights, the increase of the tree model submergence resulted in a weaker wave impact on the mangrove models. This pattern can be particularly well observed for non-breaking waves (EM1). In case of non-breaking waves (EM1), the forces exerted by waves on single mangrove tree models of $H_{\mathrm{i} \text {, nom }}=0.04 \mathrm{~m}$ on the first tree row were ca. $1.2 \mathrm{~N}$ for water depth $h=0.515 \mathrm{~m}$, ca. $0.6 \mathrm{~N}$ for $h=0.565 \mathrm{~m}$ and ca. $0.4 \mathrm{~N}$ for $h=0.615 \mathrm{~m}$. For these conditions, the forces were reduced at the last tree row to ca. $0.8 \mathrm{~N}$ for $h=0.515 \mathrm{~m}$, ca. $0.5 \mathrm{~N}$ for $h=0.565 \mathrm{~m}$ and ca. $0.3 \mathrm{~N}$ for $h=0.615 \mathrm{~m}$, irrespective of the forest width (see Fig. 11a). In comparison to higher non-breaking waves of $H_{\mathrm{i} \text {, nom }}=0.08 \mathrm{~m}$ propagating in water depth of $h=0.615 \mathrm{~m}$, the exerted forces were much larger - ca. $1.7 \mathrm{~N}$ and $1.4 \mathrm{~N}$ at the beginning and at the end of the forest model, respectively. 
Waves breaking over the beach slope (EM2) at water depth $h=0.465 \mathrm{~m}$ exerted forces of ca. $2.8 \mathrm{~N}$ for $H_{\mathrm{i}, \text { nom }}=0.12 \mathrm{~m}$, ca. $4.7 \mathrm{~N}$ for $H_{\mathrm{i}, \text { nom }}=0.16 \mathrm{~m}$ and ca. $5.5 \mathrm{~N}$ for $H_{\mathrm{i}, \text { nom }}=0.20 \mathrm{~m}$ at the beginning of the forest (Fig. 11b). The magnitude of the forces exerted at the last tree row was clearly dependent on the propagation distance of the broken waves and the associated energy dissipation. Exemplarily, these forces were ca. $3.6 \mathrm{~N}$ in the case of waves of $H_{\mathrm{i}, \text { nom }}=0.16 \mathrm{~m}$ and $B=0.75 \mathrm{~m}$, ca. $2.3 \mathrm{~N}$ for $B=1.5 \mathrm{~m}$, ca. $2.0 \mathrm{~N}$ for $B=2.25 \mathrm{~m}$ and ca. $1.5 \mathrm{~N}$ for $B=3.0 \mathrm{~m}$.

Similarly to the waves classified as EM2, the magnitude of the forces exerted by waves breaking in front of the forest model (EM3) was strongly conditioned by the location of the incipient wave breaking and the rate of the additional energy losses achieved before the waves reached the first tree row. The effect of the incident wave height on the magnitude of the forces exerted on the frontal tree row can be clearly seen in Fig. 11b. For the constant water depth $h=0.465 \mathrm{~m}$, the forces at the beginning of the forest increased from ca. $1.4 \mathrm{~N}$ for $H_{\mathrm{i}, \text { nom }}=0.04 \mathrm{~m}$ to ca. $2.3 \mathrm{~N}$ for $H_{\mathrm{i}, \text { nom }}=0.08 \mathrm{~m}$. Depending on the forest width, these forces were reduced at the end of the forest model to ca. $0.8 \mathrm{~N}$ and $0.2 \mathrm{~N}$ for $H_{\mathrm{i}, \text { nom }}=0.04 \mathrm{~m}$, while for $H_{\mathrm{i}, \text { nom }}=0.08 \mathrm{~m}$ to ca. $1.5 \mathrm{~N}$ and $0.5 \mathrm{~N}$ for $B=1.5$ and $3.0 \mathrm{~m}$, respectively. The increase of the water depth caused a shifting of the location of the incipient wave breaking with respect to the front face of the forest model. Therefore, the tendency of the forces to decrease with the increasing tree submergence depth for nonbreaking waves cannot be clearly observed in this case. Exemplarily for $H_{\mathrm{i}, \text { nom }}=0.2 \mathrm{~m}$, the forces at the beginning of the forest yielded ca. $5.2 \mathrm{~N}$ for $h=0.515 \mathrm{~m}$, for $h=0.565 \mathrm{~m}$ were smaller (ca. $3.4 \mathrm{~N}$ ) and increased up to ca. $6.5 \mathrm{~N}$ for $h=0.615 \mathrm{~m}$, since the breaking was induced much closer to the first tree row. For these wave conditions, the maximum reduction of the wave-induced forces was achieved for the widest forest width (i.e. $B=3.0 \mathrm{~m}$ ): ca. $2.0-2.2 \mathrm{~N}$ for all considered water depths (Fig. 11a).

For waves classified as EM4, the forces decreased first up to the location of the inception point of wave breaking. The breaking waves exerted additional load on the tree models, which is indicated by a slight local increase of the forces in the forest model (Fig. 11a). For example the forces exerted by wave of $H_{\mathrm{i} \text {, nom }}=0.12 \mathrm{~m}$ at water depth $h=0.615 \mathrm{~m}$ were reduced from ca. $4.1 \mathrm{~N}$ at force transducers FTS1/FTS2 to ca. $2.5 \mathrm{~N}$ at FTS8. At transducer FTS9 the force reached $4.2 \mathrm{~N}$ due to the induced wave breaking and decreased with the wave propagation up to ca. $1.8 \mathrm{~N}$ at FTS10.

Waves breaking behind the forest model (EM5) experienced a very similar behaviour as waves classified as EM4. In this case, however, the slight force amplification can be observed at the last tree row of the forest of width $B=0.75 \mathrm{~m}$. Exemplarily, the forces exerted by waves of $H_{\mathrm{i}, \text { nom }}=0.08 \mathrm{~m}$ at water depth $h=0.565 \mathrm{~m}$ were $3.0 \mathrm{~N}$ at transducers FTS1/FTS4/FTS7, 2.1 N at transducers FTS2/FTS5/FTS8 and $3.3 \mathrm{~N}$ at transducers FTS3/FTS6/FTS9.
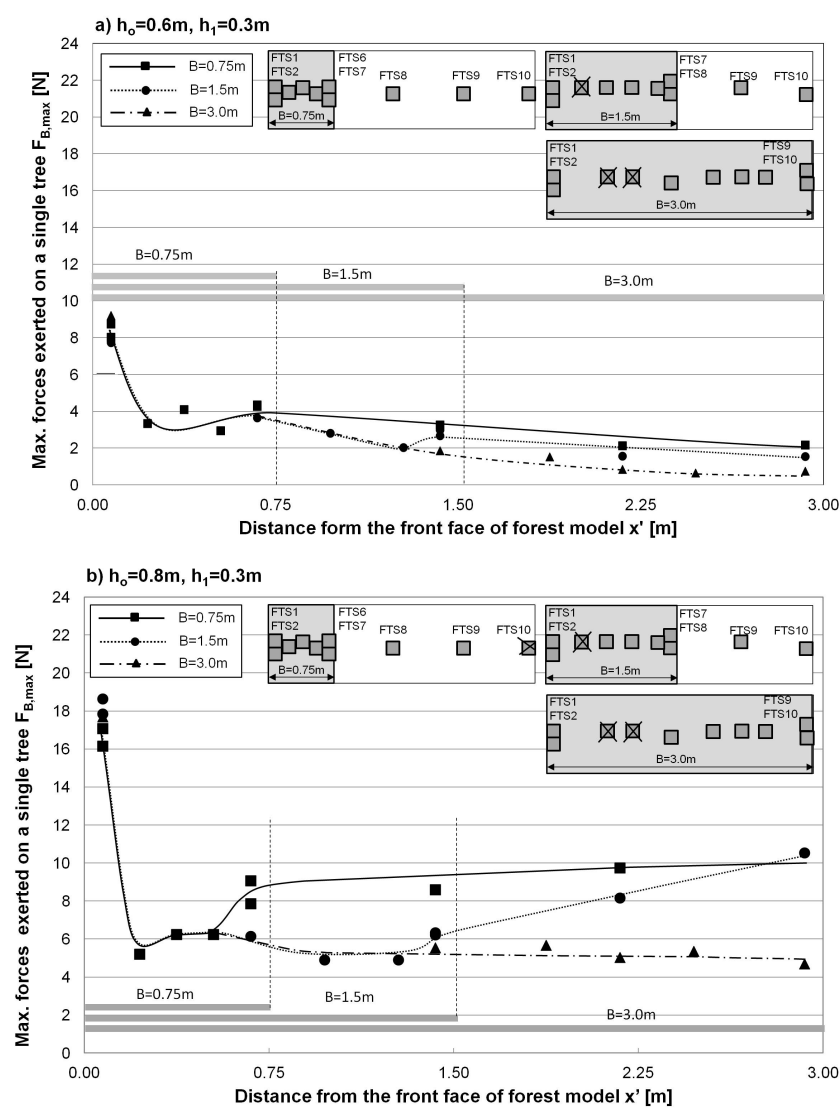

Fig. 12. Selected envelopes of forces exerted by tsunami bores on single mangrove tree models: (a) in case of water depth behind bore gate $h_{\mathrm{o}}=0.6 \mathrm{~m}$ and water depth in front of bore gate $h_{1}=0.3 \mathrm{~m}$, (b) in case of water depth behind bore gate $h_{\mathrm{o}}=0.8 \mathrm{~m}$ and water depth in front of bore gate $h_{1}=0.3 \mathrm{~m}$ (see Fig. 6 and Table 3 for force transducer locations).

\subsubsection{Envelope of forces exerted by tsunami bores on single mangrove models}

The bore approaching the forest model as a turbulent water wall exerted much greater load on the frontal tree row (even up to a factor of 4) in comparison to the solitary waves. The bore-induced forces ranged within ca. 8.0-24.0 N, while only ca. $0.4-6.0 \mathrm{~N}$ for solitary waves. These results clearly indicate the appropriateness of the application of a bore for the reconstruction of the destructive nature of a tsunami under laboratory conditions.

Exemplary envelopes of the bore-induced forces are plotted in Fig. 12a and b for all examined forest widths (in this case $B=0.75,1.5$ and $3.0 \mathrm{~m}$ ). The experimental data show a clear tendency of the forces recorded at the first forest row to increase with the rising water level $h_{\mathrm{o}}$ behind the bore gate, with a negligible effect of water level $h_{1}$ in front of the gate at the same time: ca. $8.0 \mathrm{~N}$ was measured for $h_{\mathrm{o}}=0.6 \mathrm{~m}$, ca. $12.0 \mathrm{~N}$ for $h_{\mathrm{o}}=0.7 \mathrm{~m}$, ca. $17.0 \mathrm{~N}$ for $h_{\mathrm{o}}=0.8 \mathrm{~m}$ and the largest forces of ca. $24.0 \mathrm{~N}$ for $h_{\mathrm{o}}=0.9 \mathrm{~m}$. 
Similar to the experiments with the solitary waves, the widest forest model (i.e. $B=3.0 \mathrm{~m}$ ) was found to be most effective in tsunami bore attenuation. For water depth $h_{\mathrm{o}}=0.6 \mathrm{~m}$, the forces in the last tree row were reduced for $B=0.75,1.5$ and $3.0 \mathrm{~m}$ to ca. $4.0,2.3$ and $0.05 \mathrm{~N}$; for $h_{\mathrm{o}}=0.7 \mathrm{~m}$ to ca. $6.0,5.0$ and $3.5 \mathrm{~N}$; for $h_{\mathrm{o}}=0.8 \mathrm{~m}$ to ca. 8.5 , $6.5,5.0 \mathrm{~N}$ and finally for $h_{\mathrm{o}}=0.9 \mathrm{~m}$ to ca. $10.0,8.0$ and $6.2 \mathrm{~N}$. A complete bore damping was observed for the weakest bore generated with the water level behind the bore gate of $0.6 \mathrm{~m}$, propagating over the forest model of width $B=3.0 \mathrm{~m}$ (Fig. 12a).

The improved arrangement of the force transducers in the experiments with the tsunami bores allowed to determine the force envelope within as well as behind the forest model. The most detailed force pattern in the mangrove forest was obtained solely for the smallest tested forest width of $B=0.75 \mathrm{~m}$, for which each tree along the forest width was connected to a force transducer. Such detailed force measurements were not possible in the tests with greater forest widths. Therefore, no force pattern in the five first tree rows are shown in Fig. 12 for $B=1.5$ and $3.0 \mathrm{~m}$. However, it is expected that the force trend is similar for all forest widths within the first five tree rows and the first discrepancy appears at the end of the narrowest forest, where the forces generally increased as the bore exited the forest model. During further bore propagation through the forest of widths $B=1.5$ and $3.0 \mathrm{~m}$, the magnitude of the exerted forces was also the same until the end of the forest of width $B=1.5 \mathrm{~m}$, where the force became generally larger as the bore entered the region behind the forest model. The forces of the bore travelling further over the widest forest decreased until reaching the end of the forest.

As indicated by the results obtained for $B=0.75 \mathrm{~m}$, the largest bore attenuation occurred in the first two forest rows and it continued up to the fourth tree row (Fig. 12). From there, a sudden increase of the forces can be observed (for all investigated forest widths and water depths behind the bore gate) as the bore entered the forest-free region. The forces recorded behind the forest tended to decrease for the weakest bores (generated at the smallest water depth behind the bore gate): up to ca. $2.0 \mathrm{~N}$ for $h_{\mathrm{o}}=0.6 \mathrm{~m}$ and slightly below $6.0 \mathrm{~N}$ for $h_{\mathrm{o}}=0.7 \mathrm{~m}$.

For forest width $B=1.5 \mathrm{~m}$, the forces behind the forest decreased solely for the weakest bore to ca. $2.0 \mathrm{~N}$ and increased for the larger $h_{\mathrm{o}}$, reaching ca. $6.0 \mathrm{~N}$ for $h_{\mathrm{o}}=0.7 \mathrm{~m}$, ca. $11.0 \mathrm{~N}$ for $h_{\mathrm{o}}=0.8 \mathrm{~m}$ and ca. $14.0 \mathrm{~N}$ for $h_{\mathrm{o}}=0.9 \mathrm{~m}$ (Fig. 12).

The forces decreased over the entire forest width in the direction of bore propagation in case of the widest forest model $B=3.0 \mathrm{~m}$ (Fig. 12). The difference in the magnitude of the forces exerted in the second/third tree row and at the end of the forest of $B=3.0 \mathrm{~m}$ is relatively small.
The detailed force measurements, particularly at the beginning of the forest model, show that the first four tree rows are already capable of reducing the bore impact. Despite the force reduction within the forest belt $(B=18.75 \mathrm{~m}$ in prototype), the area behind such a short forest would however suffer great damage as the bore forces increase when exiting the forest. In order to maintain the force reduction rate, which was already achieved within the first few tree rows, a wider forest is required - minimum $3.0 \mathrm{~m}(B=75 \mathrm{~m}$ in prototype) as indicated by the experimental results. However, further investigations would be required to obtain the actual force pattern behind the forest.

\section{Determination of tsunami transmission through the mangrove forest}

\subsection{Solitary wave transmission}

In the engineering practice, the effectiveness of an arbitrary protective structure is usually described by wave transmission coefficients, expressed as a ratio of the transmitted wave height to the incident wave height. As indicated by the analysis of the wave height envelope in Sect. 4.2.1, the height of the transmitted solitary wave very often exceeded that of the incident wave as a result of the wave fission process (Fig. 7). In this case, the value of the so-defined transmission coefficient would be unrealistic, i.e. $K_{\mathrm{t}}>1.0$. Using the analogy to the aforementioned method of the determination of wave transmission coefficient $K_{\mathrm{t}}$, a ratio of the forces exerted on single tree models located at the end and at the beginning of the forest model was used:

$K_{\mathrm{t}}=F_{\mathrm{e}} / F_{\mathrm{b}}$,

where $F_{\mathrm{b}}$ represents the maximum wave-exerted force on a single mangrove model located at the beginning of a forest model $[\mathrm{N}]$ and $F_{\mathrm{e}}$ the maximum wave-exerted force on a single mangrove model located at the end of a forest model [N]. For forest width $B=0.75 \mathrm{~m}$, forces measured by force transducers FTS7 and FTS9 represent the forces exerted at the frontal and rear forest rows, respectively; for $B=1.5$ and $2.25 \mathrm{~m}$ an average of the forces at transducers FTS1/FTS2 and FTS10, respectively; for $B=3.0 \mathrm{~m}$ the forces at transducers FTS1 and FTS10, respectively (Fig. 6 and Table 3).

The solitary wave transmission coefficients are plotted in Fig. 13a versus relative forest width $B / L_{\mathrm{i}}$, gen (where $B$ is the forest width and $L_{\mathrm{i} \text {, gen }}$ the generated incident wave length), which was found to be the most important parameter affecting the forest damping performance. The generated incident solitary wave length, which is theoretically infinite, was approximated by means of the following formula proposed by Dean and Dalrymple (1991):

$L_{\mathrm{i}, \text { gen }}=2 \frac{2.12 h}{\sqrt{H_{\mathrm{i}, \text { gen }} / h}}$, 

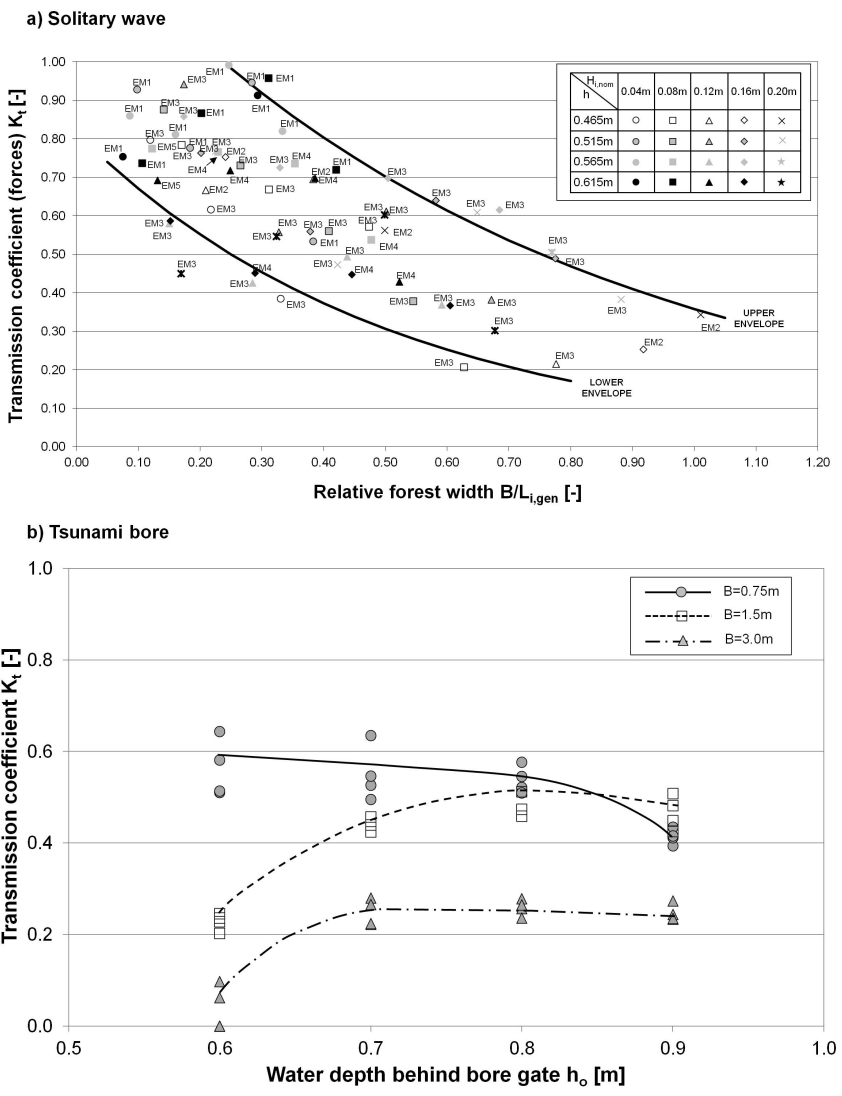

Fig. 13. Transmission coefficient for: (a) solitary wave, plotted as a function of relative forest width $B / L_{\mathrm{i}}$, gen for different wave evolution modes EM1-EM5, (b) tsunami bore, plotted as a function of water depth behind bore gate $h_{\mathrm{o}}=0.6-0.9 \mathrm{~m}$ (for water depth in front of bore gate $h_{1}=0.0-0.3 \mathrm{~m}$ ).

where $h$ is the total water depth [m] and $H_{\mathrm{i} \text {, gen }}$ the generated incident wave height $[\mathrm{m}]$.

The range of the relative forest width corresponding to non-breaking waves (wave evolution mode EM1) was $B / L_{\mathrm{i}, \text { gen }}=0.14-0.4$ and wave transmission coefficient varied from $K_{\mathrm{t}}=0.53$ to $K_{\mathrm{t}}=0.992$, depending on water depth and forest width. Slightly lower values of the transmission coefficient $\left(K_{\mathrm{t}}=0.34-0.75\right)$ were obtained for waves breaking over the beach slope (EM2) for relative forest width $B / L_{\mathrm{i}, \text { gen }}=0.21-1.0$. Transmission coefficient for waves classified as EM3 reached $K_{\mathrm{t}}=0.43-0.94$ for $B / L_{\mathrm{i}, \mathrm{gen}}=0.12-0.88$. Waves breaking in the forest model (EM4) were characterized by a similar rate of wave transmission to that of EM2 $\left(K_{\mathrm{t}}=0.43-0.77\right)$, which was however attributed to a narrower range of the relative forest width $\left(B / L_{\mathrm{i}, \text { gen }}=0.23-0.52\right)$. For waves breaking behind the forest model (EM5), the wave transmission reached $K_{\mathrm{t}}=0.69-0.77$ for $B / L_{\mathrm{i}, \text { gen }}=0.12-0.13$.

The significant contribution of the local foreshore topography to wave attenuation, through wave breaking, becomes very clear when comparing the damping performance of the forest model under non-breaking and breaking wave conditions. In fact, the highest rate of wave transmission was observed for non-breaking waves, indicating a much lower effectiveness of the investigated mangrove model than reported from field surveys (e.g. Dahdoh-Guebas et al., 2005; UNEP Report, 2005; EJF Report, 2006). The highest reduction of wave energy can be achieved solely by the combined effects of the forest and the foreshore topography. Depending on the local water depth and incident conditions, the transmission coefficient may vary significantly for different evolution modes within the lower and upper envelops shown in Fig. 13a.

Huang et al. (2011) investigated experimentally and numerically, predominantly, the effect of drag coefficient on solitary wave transmission over a group of cylinders of varying width, arrangement, $V_{\mathrm{m}} / V$ ratio and density, installed on a horizontal flume bottom. The smallest wave transmission (calculated in terms of incident and transmitted wave heights) was achieved for the aligned vegetation model: $K_{\mathrm{t}}=0.4-0.5$ for $C_{\mathrm{D}}=1.7-3.3$ (model width $\left.0.545 \mathrm{~m}, V_{\mathrm{m}} / V=0.175\right)$. For this data set, the following fitting curve was proposed by Huang et al. (2011):

$K_{\mathrm{t}}=0.579-0.069 C_{\mathrm{D}}$.

Equation (9) is however valid for the following range of the drag coefficient: $C_{\mathrm{D}}=1.0-3.5$. The influence of the forest width on the rate of wave transmission was discussed by Huang et al. (2011) on an example of a staggered model with a doubled distance among the cylinders, resulting in a smaller vegetation density. For incident wave height of $0.04 \mathrm{~m}$ at water depth of $0.15 \mathrm{~m}$, ca. $K_{\mathrm{t}}=0.82$ for $B=0.545 \mathrm{~m}$ and ca. $K_{\mathrm{t}}=0.6$ for $B=1.635 \mathrm{~m}$ were obtained. A similar transmission coefficient $\left(K_{\mathrm{t}}=0.86\right)$ was obtained in this study for the smallest forest width of $B=0.75 \mathrm{~m}$ and $h=0.515 \mathrm{~m}$, which would correspond to vegetation width of $B=0.545 \mathrm{~m}$ and tree submergence depth of $0.15 \mathrm{~m}$ in the experiments by Huang et al. (2011). Unlike Huang et al. (2011), a much higher transmission $\left(K_{\mathrm{t}}=0.81\right)$ was however observed in this study for same vegetation submergence depth of $0.15 \mathrm{~m}$ and the forest of width $B=1.5 \mathrm{~m}(B=1.635 \mathrm{~m}$ in the tests by Huang et al., 2011).

\subsection{Tsunami bore transmission}

Selected time histories of tsunami bore height and boreinduced forces, on single mangrove models in front of and behind the forest models of varying width, are exemplarily shown in Fig. 14. As already mentioned in Sect. 4.1.2, tsunami bores approaching the forest model were blocked by the first three tree rows. The strong water accumulation (set up) at the front face of the forest model led to a strong amplification of the bore height in comparison to the bore height measured in front of the forest model. The increase of the bore height at wave gauge WG5 became larger with widening of the forest model (Fig. 14a). Such amplification of the 


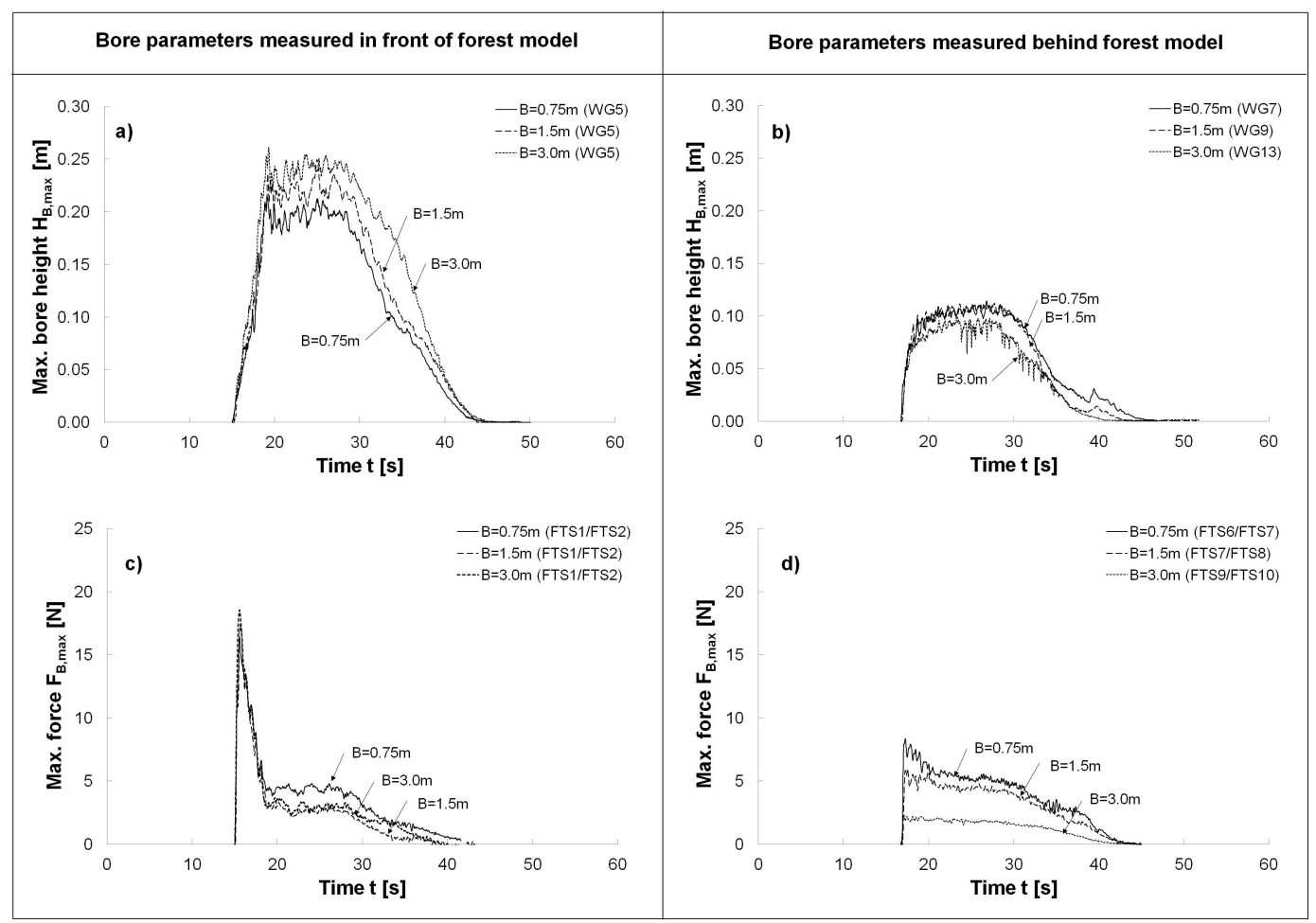

Fig. 14. Selected time histories of bore parameters (water depth behind bore gate $h_{\mathrm{o}}=0.8 \mathrm{~m}$, water depth in front of bore gate $h_{1}=0.3 \mathrm{~m}$ ): $(\mathbf{a}, \mathbf{b})$ bore height in front of and behind forest model, respectively; (c, d) bore-induced forces exerted on single tree models in front of and behind forest model, respectively (see also Fig. $5 \mathrm{~b}$ for wave gauge locations; Fig. 6 and Table 1 for force transducer locations).

forces exerted on single mangrove trees was not observed (see Fig. 14c) and therefore the same approach for the determination of the transmission coefficient was used as in case of solitary waves (Förstner, 2010; Geiling, 2011a, b).

Forces exerted at the front face of the forest model $F_{\mathrm{b}}$ were determined from the measurements of force transducers FTS1/FTS2, irrespective of the forest width. The forces measured by transducers FTS6/FTS7 for forest width $B=0.75 \mathrm{~m}$, transducers FTS7/FTS8 for $B=1.5 \mathrm{~m}$, and transducers FTS9/FTS10 for $B=3.0 \mathrm{~m}$ were used to represent forces exerted at the end of the forest model $F_{\mathrm{e}}$ (Table 3 ).

The pattern of the bore transmission coefficient is shown in Fig. $13 \mathrm{~b}$ as a function of water level behind the bore gate $h_{\mathrm{o}}$ and forest width $B$. As expected, the transmission of the tsunami bore became smaller when increasing the width of the forest model from $B=0.75 \mathrm{~m}$ to $B=3.0 \mathrm{~m}$. For the two largest forest widths examined, a significant increase of the transmission coefficient can be observed at the transition from the water depth $h_{\mathrm{o}}=0.6 \mathrm{~m}$ to $h_{\mathrm{o}}=0.7 \mathrm{~m}$. In addition, the effect of the water level in front of the bore gate on the rate of the bore transmission can be rather neglected. In case of forest width $B=1.5 \mathrm{~m}$, the transmission coefficient was ca. $K_{\mathrm{t}}=0.24$ for $h_{\mathrm{o}}=0.6 \mathrm{~m}$, and it reached an approximately constant value of $K_{\mathrm{t}}=0.5$ for $h_{\mathrm{o}}=0.7-0.9 \mathrm{~m}$. The largest reduction of the bore energy was attributed to the widest forest of $B=3.0 \mathrm{~m}$ - the transmission coefficient was only ca. $K_{\mathrm{t}}=0.1$ for $h_{\mathrm{o}}=0.6 \mathrm{~m}$ and $h_{1}=0.2,0.3 \mathrm{~m}$ (there was no bore transmission for $h_{1}=0.0,0.1 \mathrm{~m}$ ), while it increased to ca. $K_{\mathrm{t}}=0.25$ for $h_{\mathrm{o}}=0.7-0.9 \mathrm{~m}$. A different pattern of the bore transmission was identified for the narrowest forest model of $B=0.75 \mathrm{~m}$. In this case the transmission coefficient remained approximately constant $\left(K_{\mathrm{t}}=0.59\right)$ for the water level behind the bore gate $h_{\mathrm{o}}=0.6-0.8 \mathrm{~m}$. The further increase of the water depth behind the bore gate to $h_{\mathrm{o}}=0.9 \mathrm{~m}$ was accompanied by a significant reduction of the bore transmission to ca. $K_{\mathrm{t}}=0.41$, which is not so clear for the other forest widths.

Unlike the tests with the solitary waves, it is not possible to distinguish between the effect of the forest and the foreshore topography on the wave attenuation. Due to the turbulent nature of the generated bores, the additional source of the bore energy dissipation was already included in the measured data.

\section{Flow resistance of single mangrove models under solitary wave conditions}

The resistance of a single mangrove tree in the forest model, subjected to solitary wave impact, was determined in terms of drag and inertia coefficients by means of the least square method. Given total measured forces $F_{\text {meas }}$, predicted total 
forces $F_{\text {pred }}$ result from Morison's equation:

$F_{\text {pred }}=\lambda_{\mathrm{D}} \cdot u^{2}+\lambda_{\mathrm{m}} \frac{\partial u}{\partial t}$,

with $\lambda_{\mathrm{D}}$ and $\lambda_{\mathrm{m}}$ defined as:

$\lambda_{\mathrm{D}}=0.5 \rho \cdot A_{\mathrm{f}} \cdot C_{\mathrm{D}}$,

$\lambda_{\mathrm{m}}=\rho \cdot V_{\mathrm{m}} \cdot C_{\mathrm{M}}$.

The total quadratic error between the measured and the predicted forces is determined as follows:

$\varepsilon^{2}=\sum\left[F_{\text {pred }}-F_{\text {meas }}\right]^{2}=\sum\left[\lambda_{\mathrm{D}} \cdot u^{2}+\lambda_{\mathrm{m}} \frac{\partial u}{\partial t}-F_{\text {meas }}\right]^{2}$,

where $A_{\mathrm{f}}$ is the frontal area of the tree model $\left[\mathrm{m}^{2}\right], C_{\mathrm{D}}$ the drag coefficient [-], $C_{\mathrm{M}}$ the inertia coefficient, $F_{\text {pred }}$ the predicted forces $[\mathrm{N}], F_{\text {meas }}$ the measured forces $[\mathrm{N}]$ exerted on a single tree model located in the first tree row (measured by force transducer FTS4 for $B=0.75 \mathrm{~m}$ and by FTS1 for $B=1.5,2.25$ and $3.0 \mathrm{~m}), u$ the flow velocity $\left[\mathrm{m} \mathrm{s}^{-1}\right]$ in front of the forest (see Sect. 3.3), $V_{\mathrm{m}}$ the volume of a submerged part of a tree model $\left[\mathrm{m}^{3}\right], \rho$ the water density $\left[\mathrm{kg} \mathrm{m}^{-3}\right]$ and $\partial u / \partial t$ the flow acceleration $\left[\mathrm{m} \mathrm{s}^{-2}\right]$.

Since the quadratic total error is required to be kept at minimum, the first derivation of the quadratic error should be equal to zero:

$\partial \varepsilon^{2} / \partial \lambda_{\mathrm{D}}=0$

$\partial \varepsilon^{2} / \partial \lambda_{M}=0$.

By inserting Eq. (13) into Eqs. (14) and (15), one obtains two equations that can be re-arranged in the following matrix:

$$
\left[\begin{array}{cc}
\sum u^{4} & \sum u^{2} \frac{\partial u}{\partial t} \\
\sum u^{2} \frac{\partial u}{\partial t} & \sum\left(\frac{\partial u}{\partial t}\right)^{2}
\end{array}\right]\left\{\begin{array}{l}
\lambda_{\mathrm{D}} \\
\lambda_{\mathrm{M}}
\end{array}\right\}=\left\{\begin{array}{c}
\sum u^{2} F_{\text {meas }} \\
\sum \frac{\partial u}{\partial t} F_{\text {meas }}
\end{array}\right\} .
$$

The drag and inertia coefficients were determined from Eqs. (10) and (11) by inserting the computed values of $\lambda_{D}$ and $\lambda_{m}$, obtained by solving Eq. (16) with the flow velocity and total force data provided from the experiments.

Due to the required $5 \mathrm{~cm}$-freeboard below the ADV sensor, reliable flow velocity measurements were possible solely for the two highest water depths (i.e. $h=0.515$ and $0.615 \mathrm{~m}$ ). In case of water depth of $h=0.565 \mathrm{~m}$, the frontal area of the single model was $A_{\mathrm{f}}=73.84 \mathrm{~cm}^{2}$ and the corresponding volume of the submerged tree model was $V_{\mathrm{m}}=97.3 \mathrm{~cm}^{3}$. For water depth of $h=0.615 \mathrm{~m}$, these two parameters increased to $A_{\mathrm{f}}=76.24 \mathrm{~cm}^{2}$ and $V_{\mathrm{m}}=98.8 \mathrm{~cm}^{3}$.

The drag and inertia coefficients are plotted for these conditions in Fig. 15 as a function of the Reynolds number $R e$, as defined by Eqs. (3) and (4), in order to account for the physical properties of the tree models.
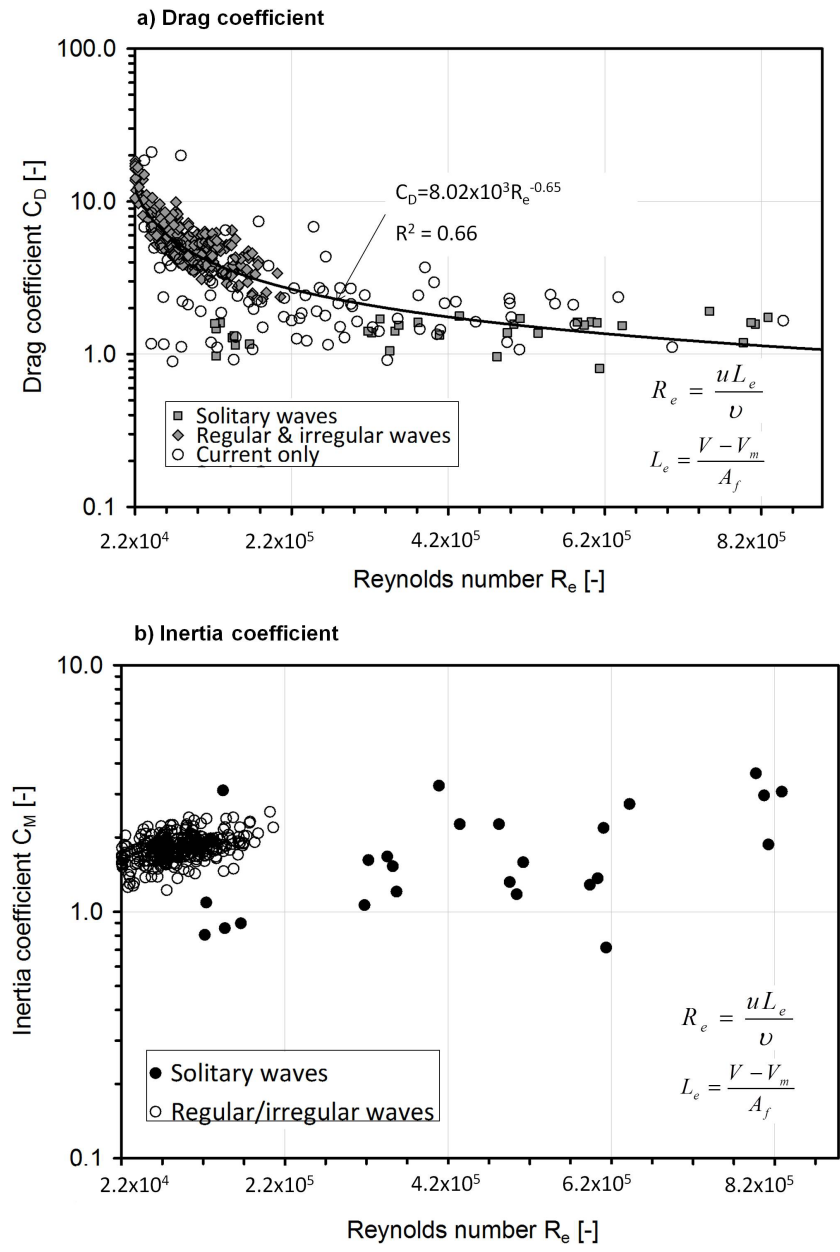

Fig. 15. Flow resistance of mangrove models subject to solitary wave impact in comparison to other investigated flow regimes: (a) drag coefficient, (b) inertia coefficient.

The drag coefficient ranges between $C_{\mathrm{D}}=0.8$ and $C_{\mathrm{D}}=1.9$, and tends to remain constant over the entire investigated range of the Reynolds number obtained for solitary waves $\left(\operatorname{Re}=1.24 \times 10^{5}-1.2 \times 10^{6}\right)$. Such a behaviour of the drag coefficient was also found by e.g. Imai and Matsutomi (2005), Yanagisawa et al. (2009) and Huang et al. (2011). The resistance of the mangrove models subject to solitary wave impact was compared in Fig. 15a to that obtained under the quasi-steady flow (Fig. 3 in Sect. 2.2) and regular/irregular wave conditions (Husrin, 2012). Lower values of the drag coefficient attributed to the solitary waves resulted from a lower ratio of $V_{\mathrm{m}} / V$ and lower flow velocities as compared to the other considered flow regimes. The solitary waves-related drag coefficient represents the lower boundary of the mangrove resistance for all considered flow regimes, oscillating around the value attributed to a single cylinder $\left(C_{\mathrm{D}}=1.2\right)$. The latter is very often applied to represent vegetation resistance subject to tsunami impact (e.g. Dekker, 2006; Teo, 2008; Yanagisawa et al., 2009). The 
following formula for the drag coefficient, valid for regular/irregular waves, solitary waves and current is proposed:

$C_{\mathrm{D}}=8.02 \times 10^{3} R e^{-0.65}$,

with the Reynolds number Re determined according to Eqs. (3) and (4).

A similar relationship between drag coefficient and Reynolds number was also determined by Mazda et al. (1997) for mangrove swamps in Japan (dominated by Bruguiera gymnorrhiza and Rhizophora stylosa) and Australia (dominated by Rhizophora stylosa), subject to tidal flow. Under these conditions, a relatively small range of the Reynolds number was however obtained (up to $\left.R e=9 \times 10^{4}\right)$ in comparison to the present study. Maximum drag coefficient reached $C_{\mathrm{D}}=10$ for a much smaller Reynolds number of $R e=10^{4}$, which is consistent with the present results, and it decreased up to $C_{\mathrm{D}}=0.4$ as the flow became more turbulent $\left(R e>5 \times 10^{4}\right)$. Such a low value of the drag coefficient can result from the additional flow reduction due to bottom friction and presence of shrubs.

The following function of drag coefficient in terms of volume of submerged mangroves $V_{\mathrm{m}} / V$ was provided by Harada and Imamura (2001):

$C_{\mathrm{D}}=8.4 V_{\mathrm{m}} / V+0.66$,

for the case of a broken, long wave propagating through a forest model. The models of Rhizophora sp. were designed under the consideration of the dimensions of trees in nature and consisted of a porous root system, cylindrical trunk and porous canopy. In case of no vegetation (i.e. for $V_{\mathrm{m}} / V=0$ ), Eq. (18) predicts however very high drag coefficient $\left(C_{\mathrm{D}}=0.66\right)$, which makes this equation physically questionable.

Imai and Matsutomi (2005) suggested a drag coefficient in a range of $C_{\mathrm{D}}=0.9-1.5$ for a case of tsunami bore interaction with a forest of varying density $(0.5-1.5 \%)$, consisting of plastic pine tree models arranged in staggered and tandem rows on a sand spit. For a simplification of the calculations of the exerted forces, the volume and the projection area of the considered tree models were replaced by an equivalent volume and an equivalent projection area of cylinders. The values of the drag coefficient were found to be strongly dependent on the vegetation density and weakly dependent on the relative bore height. However, the lack of a parameterization method for a representative pine tree model makes the applicability of these results indeed questionable.

Huang et al. (2011) determined drag coefficient on a basis of own experiments with a solitary wave propagating over a vegetation model made of rigid cylinders of varying aligned and staggered arrangement. The results were completed by experimental data by Tanino and Nepf (2008), obtained for randomly arranged cylinders. Similar to the work by Harada and Imamura (2001), the drag coefficient was also expressed in terms of the submerged volume ratio:

$$
C_{\mathrm{D}}=1.24+4.59 \frac{V_{\mathrm{m}} / V}{1-V_{\mathrm{m}} / V} .
$$

The value of $C_{\mathrm{D}}=1.24$ obtained for $V_{\mathrm{m}} / V$ equal zero (i.e. no vegetation) is similar to that for a single cylinder and cannot be satisfactorily explained. Equation (19) is therefore, like in the case of Eq. (18), physically questionable.

The inertia coefficient attributed to solitary and regular/irregular waves is plotted in Fig. 15b. Unlike Huang et al. (2011), the contribution of the inertia coefficient to the total vegetation resistance was found to be important, particularly under breaking wave conditions, causing more significant flow acceleration than in case of nonbreaking waves. The inertia coefficient varied in this study from $C_{\mathrm{M}}=0.7$ to $C_{\mathrm{M}}=4.6$ for a Reynolds number range $R e=1.24 \times 10^{5}-1.2 \times 10^{6}$, with the averaged value of 1.81 , which is identical to that obtained for regular/irregular waves (Husrin, 2012).

In the study of Harada and Imamura (2001), a very similar value of the inertia coefficient $\left(C_{\mathrm{M}}=1.7\right)$ was obtained. Latief and Hadi (2006) proposed on the other hand a smaller value of the inertia coefficient of $C_{\mathrm{M}}>1.0$, valid however for the ratio $V_{\mathrm{m}} / V>0.06$, which is much smaller than that in the current study $\left(V_{\mathrm{m}} / V=0.02-0.2\right)$.

The hydraulic resistance of the mangrove forest under tsunami bore conditions is being investigated.

\section{Concluding remarks and outlook}

The reliability of the performance of coastal forest damping obtained from hydraulic scale modelling is very much dependent on the parameterization method applied to the tree models constituting the forest. Both physical and bio-mechanical vegetation properties should be taken into account when developing a parameterization approach, since tree age, dimensions and stiffness of each trees' structural parts determine the flow resistance of the tree. Unlike in previous studies, this aspect has been thoroughly considered in this study.

While a single cylinder might be sufficient to represent the trunk of a pine tree, more sophisticated parameterization methods are essential to simplify exemplarily the chaotic root structure of mangroves of Rhizophora sp. The application of the submerged root volume ratio, which varies with the flow depth, represents the primary feature and advantage of the mangrove parameterization approach developed in this study.

The comparative analysis of the attenuation performance of the mangrove forest, under the two investigated tsunami flow conditions (solitary wave and tsunami bore), indicates a similar minimum wave transmission despite much larger forces exerted by the tsunami bores at the first tree row than by solitary waves (with transmission coefficients expressed in terms of forces: $K_{\mathrm{t}}=20 \%$ for solitary waves and $K_{\mathrm{t}}=10 \%$ for tsunami bore, achieved for the widest 
considered forest model $B=3.0-75 \mathrm{~m}$ in prototype). This is due to the fact that the rate of tsunami damping by the forest is also strongly governed by the forest submergence conditions. The interaction of the tsunami bore with the fully exposed mangrove root system (achieved for all performed tests) was much stronger as compared to the solitary waves, propagating over a submerged root system in all conducted experiments.

For the first, time the contribution of a foreshore topography to the damping of wave energy by the forest was determined for a tsunami-like solitary wave. The distinction between non-breaking and breaking wave conditions (here additionally the location of the incipient wave breaking) is crucial for the evaluation of the forest effectiveness in the flow reduction due to the additional source of wave energy dissipation caused by the breaking event. The lowest wave transmission rate was attributed to the non-breaking wave conditions (with the minimum of $K_{\mathrm{t}}=0.53$ ), which indicates a relatively poor forest damping performance.

The most important advantages of the current study over the previous investigations are: (i) the use of a physically sound parameterization of the mangrove tree models, (ii) the wider range of the Reynolds number covered in the tests, and (iii) the incorporation of the most important physical properties of the tree models (i.e. frontal area $A_{\mathrm{f}}$, effective length $L_{\mathrm{e}}$ and vegetation occupancy volume $V_{\mathrm{m}} / V$ ) into the Reynolds number for the determination of drag and inertia coefficients.

In order to provide a complete resistance of mangrove forests to the two tsunami flow conditions examined in this study, the drag and inertia coefficients will be determined for tsunami bore conditions. Additionally, the damping performance of the mangrove forest will also be determined in terms of flow velocity attenuation. Moreover, in this paper, only the mangrove root system and the trunk (stiff structure assumption) are exposed to the tsunami induced flow. Further scale model tests with an exposed canopy are in progress. The mangrove models of the Rhizophora sp. are parameterized according to the flexible structure assumption, in which the trunk with the canopy is considered as flexible and scaled accordingly. The results will be published in a forthcoming paper.

Numerical modelling of the tsunami attenuation by mangrove forests has also been performed (Husrin, 2012). The drag and inertia coefficients, obtained from the laboratory experiments, have been implemented in the NLSW (nonlinear shallow water) model "COMCOT" (Cornell Multi-grid Coupled Tsunami Model). The model was used to reproduce the damping performance measured in the experiments reported in this paper. The results will be published in a forthcoming paper.

\section{Appendix A} Construction details of parameterized mangrove models
under stiff structure assumption
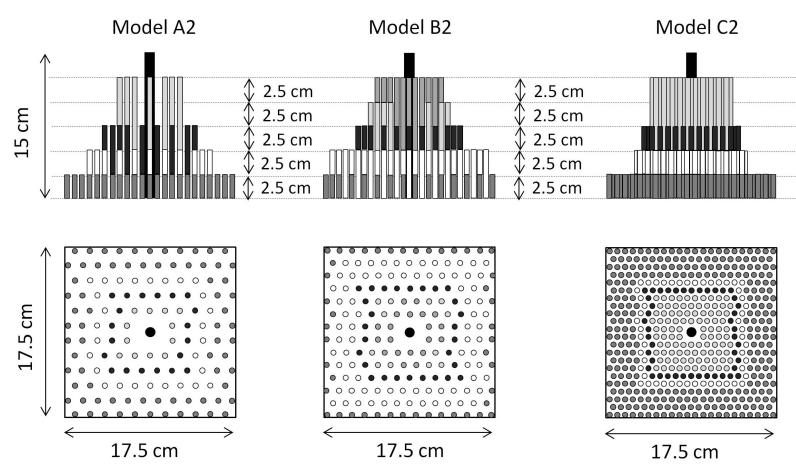

Fig. A1. Construction details of parameterized models of highest frontal area (models A2, B2, C2) at a scale of $1: 20$. Diameter of the cylinders representing mangrove roots is $0.5 \mathrm{~cm}$, diameter of cylinder representing a trunk is $1.0 \mathrm{~cm}$.
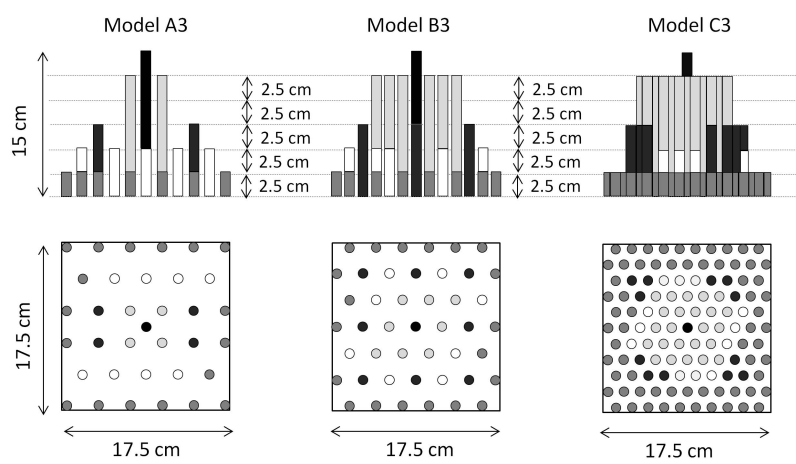

Fig. A2. Construction details of parameterized models of medium frontal area (models A3, B3, C3) at a scale of $1: 20$. Diameter of the cylinders representing mangrove roots is $1.0 \mathrm{~cm}$, diameter of cylinder representing a trunk is $1.0 \mathrm{~cm}$.
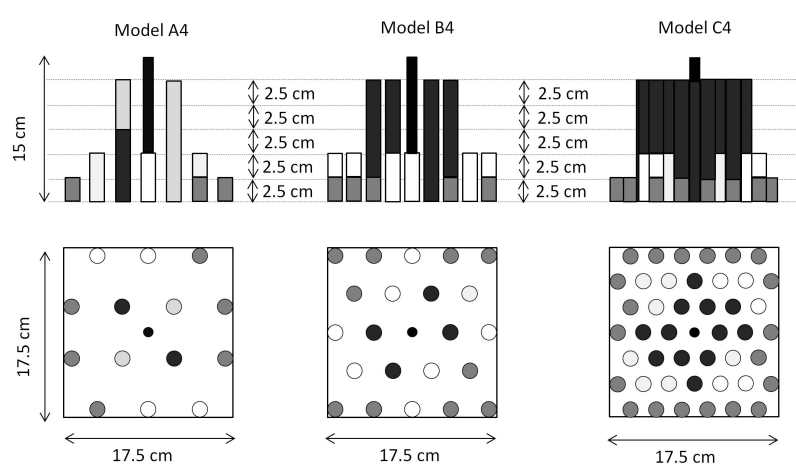

Fig. A3. Construction details of parameterized models of lowest frontal area (models A4, B4, C4) at a scale of $1: 20$. Diameter of the cylinders representing mangrove roots is $1.5 \mathrm{~cm}$, diameter of cylinder representing a trunk is $1.0 \mathrm{~cm}$. 
Acknowledgements. This study was performed in the framework of the project Tsunami Attenuation Performance of Coastal Forests (TAPFOR), which is a part of the project Tracing Tsunami impacts on- and offshore in the Andaman Sea Region (TRIAS). The authors are grateful to the Deutsche Forschungsgemeinschaft (DFG) and the Office of the Research Council of Thailand (NRCT) for the project funding (OU 1/10-1). Further financial support was provided to the second author by the DFG within the Graduate College of TU Braunschweig "Risk Management of Natural and Civilization Hazards on Buildings and Infrastructure" (GRK 802). The authors would also like to thank to Andreas Kortenhaus from the LWI for helpful comments as well as Oliver Förstner, Christina Geiling, Hanne Holtz and Andi Syukri for their significant contribution to the performance of the laboratory tests and the analysis of the experimental data. The authors would also like to thank the reviewers for their valuable comments.

Edited by: S. Tinti

Reviewed by: Z. Huang and one anonymous referee

\section{References}

Dahdouh-Guebas, F., Jayatissa, L. P., Di Nitto, D. , Bosire, J. O., Seen Lo, D., and Koedam, N.: How effective were mangroves as a defence against the recent tsunami?, Curr. Biol., 15, 443-447, 2005.

Dekker, F.: Hydrodynamics and morphodynamics in and around mangrove forests, Master thesis, University of Twente, 2006.

Dean, R. G. and Dalrymple, R. G.: Water wave mechanics for engineers and scientists, Advanced Series on Ocean Engineering, 2, World Scientific, 1991.

EERI Special Earthquake Report: Learning from Earthquakes, The Japan Tohoku Tsunami of March 11, 2011, http://www.eqclearinghouse.org/2011-03-11-sendai/files/2011/ 11/Japan-eq-report-tsunami2.pdf, 2011.

EJF Report: Mangroves: natures's defence against tsunamis - a report on the impact of mangrove loss and shrimp farm development on coastal defences, Environmental Justice Foundation, London, UK, 2006.

Förstner, O.: Attenuation of tsunami bore due to a mangrove forest, Master thesis, Dept. Hydromechanics and Coastal Engineering, TU Braunschweig, 2010.

Fritz, H. M., Borrero, J. C., Synolakis, C. E., and Yoo, J.: 2004 Indian Ocean Tsunami flow velocity measurements from survivor videos, Geophys. Res. Lett., 33, L24605, doi:10.1029/2006GL026784, 2006.

Geiling, C.: Dämpfungswirksamkeit von Mangrovenwäldern unter Tsunamibelastung in Form einer Bore - Waldbreite $B=0.75 \mathrm{~m}$, Student thesis, Dept. Hydromechanics and Coastal Engineering, TU Braunschweig, 2011a (in German).

Geiling, C.: Ausbreitung von Tsunamibore auf einem waldfreien Strand, Master thesis, Dept. Hydromechanics and Coastal Engineering, TU Braunschweig, 2011b (in German).

Harada, K. and Imamura, F.: Experimental study on the resistance by mangrove under the steady flow, Proceedings of the 1st Asian and Pacific Coastal Engineering Conference, Dalian, China, 2, 975-984, 2001.
Harada, K. and Imamura, F.: Effects of coastal forest on tsunami hazard mitigation - a preliminary investigation, Advances in Natural and Technological Hazard Research, 23, 279-292, 2005.

Huang, Z., Yao, Y., Sim, S. Y., and Yao, Y.: Interaction of solitary waves with emergent rigid vegetation, Ocean Eng., 38, 10801088, 2011.

Husrin, S.: Tsunami and storm wave attenuation by coastal forests, Ph.D. Thesis, Leichtweiß-Institute for Hydraulic Engineering and Water Resources, TU Braunschweig, Germany, submitted, 2012.

Husrin, S., Strusińska, A., and Oumeraci, H.: Experimental study on tsunami attenuation by mangrove forest, Earth, Planets Space, 64, 973-989, 2012.

Imai, K. and Matsutomi, K.: Fluid force on vegetation due to tsunami flow on a sand spit, in: Tsunamis: Case studies and recent developments, Springer, The Netherlands, 293-304, 2005.

Irtem, E., Gedik, N., Kabdasli, M. S., and Yasa, N. E.: Coastal forest effects on tsunami run-up heights, Ocean Eng., 36, 313-320, 2009.

Istiyanto, D. C., Utomo, K. S., and Suranto: Pengaruh Rumpun Bakau Terhadap Perambatan Tsunami di Pantai, Seminar Mengurangi Dampak Tsunami, Kemungkinan Penerapan Hasil Riset, BPPT - JICA, Yogyakarta, 2003 (in Indonesian).

Kongko, W.: Study on tsunami energy dissipation in mangrove forest, Master thesis, Iwate University, Japan, 2004.

Latief, H. and Hadi, S.: Protection from tsunamis, Coastal protection in the aftermath of the Indian Ocean Tsunami, What role for forests and trees?, Proceedings of the regional technical workshop, FAO, Khao Lak, Thailand, 2006.

Mazda, Y., Wolanski, E. J., King. B. A., Sase, A., Ohtsuka, D., and Magi, M.: Drag force due to vegetation in mangrove swamps, Mangroves and Salt Marshes, 1, 193-199, 1997.

Ohira, W., Honda, K., and Harada, K.: Reduction of tsunami inundation by coastal forests in Yogyakarta, Indonesia: a numerical study, Nat. Hazards Earth Syst. Sci., 12, 85-95, doi:10.5194/nhess-12-85-2012, 2012.

Shuto, N.: The effectiveness and limit of tsunami control forests, Coastal Engineering in Japan, 30, 143-153, 1987.

Tanino, Y. and Nepf, H.M.: Laboratory investigation of mean drag in a random array of rigid, emergent cylinders, J. Hydraul. Eng., 134, 34-41, 2008.

Teo, F.Y.: Attenuation of tsunami currents in an estuary with mangroves, http://www.swieet2007.org.uk/files/Fang\%20Yenn\% 20Teo\%20DD2008.pdf, 2008.

UNEP Report: Sri Lanka: post-tsunami environmental assessment, United Nations Environment Programme and Ministry of Environment \& Natural Resources of Sri Lanka, 2005.

Ward, A. D. and Trimble, S. W.: Environmental Hydrology, 2nd Edn., Lewis Publishers, USA, 2004.

Yanagisawa, H., Koshimura, S., Goto, K., Miyagi, T., Imamura, F., Ruangrassamee, A., and Tanavud, C.: The reduction effects of mangrove forest on a tsunami based on field surveys at Pakarang Cape, Thailand and numerical analysis, Estuar. Coast. Shelf S., 81, 27-37, 2009. 